\title{
LOOKING BACK AND FORGING AHEAD: THIRTY YEARS OF SOCIAL NETWORK RESEARCH ON THE WORLD-SYSTEM ${ }^{1}$
}

\author{
Paulette Lloyd \\ Department of Sociology \\ Indiana University \\ palloyd@indiana.edu \\ Matthew C. Mahutga \\ Department of Sociology \\ University of California at Riverside \\ matthew.mahutga@ucr.edu \\ Jan De Leeuw \\ Department of Statistics \\ University of California at Los Angeles \\ deleeuw@stat.ucla.edu
}

\begin{abstract}
We review three decades of research linking social network methods with world systems theory. We identify four themes nested within two versions of a general social network methodology - the identification of network Roles and Position. The themes vary by the type of data and the definition of equivalence used to identify roles and positions. Second, we provide a demonstration of the general methodological approach taken in the literature, applying a recent methodological innovation to a newly compiled large global trade dataset. The
\end{abstract}

\footnotetext{
${ }^{1}$ The first two authors are listed alphabetically to indicate equal authorship. Early versions of the paper were prepared while Paulette Lloyd was a Post-Doctoral Research Associate at the Princeton Institute for International and Regional Studies (PIIRS), and presented at a conference on global trade hosted by the PIIRS in March 2006. She thanks Miguel Centavo and PIIRS for their support. The paper was further developed for a special session on research methods for the study of the world-system at the 2007 annual meeting of the American Sociological Association. Matthew Mahutga thanks the University of California's Institute for Global Conflict and Cooperation for a grant supporting his work on the paper during this time. We thank Jeffrey Kentor, Timothy Moran, Andrew Jorgenson, Phillip Bonacich and attendees of the Princeton and ASA conferences for helpful comments and suggestions throughout. Please direct all comments and questions to Paulette Lloyd, Department of Sociology, Indiana University, 1020 E. Kirkwood Ave., Room 744, Bloomington, IN 47405, Email: palloyd@indiana.edu or Matthew C Mahutga, Department of Sociology, University of California at Riverside, 1226 Watkins Hall, Riverside, CA, 92521, Email: matthew.mahutga@ucr.edu.
} 


\section{JOURNAL OF WORLD-SYSTEMS RESEARCH}

results identify the expected core / periphery interaction pattern, suggesting that it is a fundamental feature of cross-national trade data, regardless of how the data are analyzed. We conclude by suggesting both methodological and substantive directions for future social network research on the world-system.

\section{INTRODUCTION}

At the center of the world-systems perspective is the intuition that structure (is all that) matters. Wallerstein stresses that focusing on social structure leads to a radical transformation in insight:

Once we assume that the unit of analysis is such a world system and not the state or the nation or the people, then much changes in the outcome of the analysis. Most specifically we shift from a concern with the attributive characteristics of states to concern with the relational characteristics of states. (Wallerstein 1989:xi)

It is therefore unsurprising that a thriving research tradition exists that brings together a relational-structural orientation - the world-systems perspective-with a relational-structural methodology — social network analysis (SNA).

This article's contribution to this special issue on research methods for world-systems research in the Journal of World-Systems Research is three-fold. First, we review the literature on the world-systems perspective that uses social network analysis. There are four main substantive themes addressed in this literature. These include studies which (1) assess the extent to which cross-national relational data exhibit a core / periphery structure; (2) delineate boundaries between core, periphery and semi-periphery; (3) adjudicate between the core / periphery distinction as categorical or continuous; and (4) assess the hypothesis that some form of "unequal exchange" occurs across zones of the world-system. Several studies also combine one or more of these categories with an effort to assess levels of mobility and economic growth over time. These four categories are nested within two general methodological approaches to the identification of world-system structure, which differ on what type of relational data is used. The first approach combines economic (total trade) with non-economic (treaty co-membership, military interventions, diplomatic exchanges) data (Snyder and Kick 1979). The second approach distinguishes between different types of commodity trade as the basis for analysis (Breiger 1981; Nemeth and Smith 1985).

Second, we create a detailed analysis of world trade data in order to provide a more extensive explanation for world systems scholars unfamiliar with social network methods. This section demonstrates an up to date variant of the classic Role and Position approach taken in the literature. As such, this section provides practical suggestions on decision making through each step of the analysis. This includes explaining the difference between various equivalence criterions and how to choose between them, how to conduct both categorical and continuous analyses, and how to simultaneously analyze multiple relations. Finally, this section assesses the extent to which some classic findings are "robust" to multiple methodologies by comparing our results from the Role and Position analysis to those from a recent methodological innovation, the Exponential Distance Model (EDM). 
Third, we conclude by discussing recent methodological innovations in social network analysis with an emphasis on statistical social network methods, and by suggesting potential fruitful avenues for future research. Our goal for this final section is to stimulate interest in applying social network methods to world systems research and to suggest new substantive areas for research in this area that could add to our understanding of world-systems analysis.

\section{WORLD-SYSTEMS THEORY AND NETWORK ANALYSIS: A REVIEW}

If there is anything fundamental about world-systems analysis it is the structural intuition that countries occupy stratified positions in the world-system-core, periphery and semi-periphery. While there is some debate as to whether these are qualitatively distinct positions, or rather idealtypical categories reflecting an underlying hierarchical continuum (e.g. Arrighi and Drangel 1988; c.f. Chase-Dunn and Rubinson 1977), they are overshadowed by the widespread acknowledgement that the world-system consists of a hierarchically organized structure of states, in which core countries are the most advanced, peripheral countries the least advanced, and semiperipheral countries somewhere between the other two categories.

Further, the structure of the world-system is seen as the major source of variation in the distribution of the returns to capitalist enterprise. While many mechanisms have been proposed, the central idea is that the boundary lines between core, peripheral and semi-peripheral zones of the world system demarcate distinct roles in the international division of labor and that the world economy systematically distributes wealth from peripheral and semi-peripheral countries to core countries (Wallerstein 1974). The concrete forms of economic activity that constitute core and peripheral activities have changed over the course of world-systemic development. Nevertheless, an analytical distinction between a manufactured goods-producing core and a raw material / primary goods-producing periphery has provided a useful description of the territorial division of labor in the modern world-system through roughly 1980 when the Global South experienced a dramatic rise in manufacturing activity (Chase-Dunn and Rubinson 1977; Dicken 2003).

One mechanism proposed as an explanation for inequality in the world-system is that the core's dominant position in the world-system generates the highest "concentration of innovations in new lead industries" (Chase-Dunn and Grimes 1995: 397). Thus, semi-peripheral and peripheral countries are simply excluded from the most profitable activities in the world economy (e.g. O'Hearn 2001). Another major proposed mechanism is that of "unequal exchange" (Frank 1969; Galtung 1971; Emmanuel 1972). While several variants of unequal exchange exist, they all share the view that the world-system involves an asymmetrical flow of surplus value between core and non-core countries which results in the unequal distribution of wealth. ${ }^{2}$

Social network analysis (SNA) is a structural approach to studying the relations between entities in a social system. It has its own unique concept of a core / periphery structure that parallels some of the structural lines of thought in the world-systems perspective. In SNA, a core /

\footnotetext{
${ }^{2}$ One example that fits the older territorial division of labor was the tendency for primary good prices to fall vis-à-vis the price of manufactured goods. This resulted in a greater share of surplus value accruing to the manufacturing exporter vis-à-vis the primary good exporter (Prebisch 1950; Singer 1950).
} 


\section{JOURNAL OF WORLD-SYSTEMS RESEARCH}

periphery structure is one that contains a dense and cohesive $e^{3}$ subgroup of core actors who exchange ties with one another and with a group of peripheral actors who tend to have ties with the core but not with each other, illustrating dependency (e.g. Boyd et. al 2006a; 2006b; Borgatti and Everett 1999). Thus, the core / periphery concept in social network analysis captures the extent to which a given graph has a latent core / periphery interaction pattern among actors in the network, and has been implemented across a wide array of substantive contexts, including epidemiology (Jolly et al. 2001; Christley et al. 2005), small groups (Cummings and Cross 2003), interpersonal networks (Bourgeois and Friedkin 2001), linguistics (Dodsworth 2005), groups in isolated or extreme environments (Johnson, Boster, and Palinkas 2003), networks of creative artists (Uzzi and Spiro 2005), PhD exchange networks (Burris 2004), and knowledge communities of firms (Giuliani and Bell 2005).

Table 1: Ideal-Typical Core / Periphery Structure

$\begin{array}{lccc} & \text { Core } & \text { Semi-Periphery } & \text { Periphery } \\ \text { Core } & 100 & 70 & 30 \\ \text { Semi-Periphery } & 50 & 20 & 10 \\ \text { Periphery } & 10 & 0 & 0\end{array}$

Table 1 represents an ideal-typical image matrix that reflects a social network conception of a core / periphery structure. An image matrix is a simplified representation of a set of relational data in which the rows / columns represent subgroups of actors who are similar to each other by some criterion, and the cells represent either the presence / absence of a tie (in the case of dichotomous data) or the strength of a tie (in the case of valued data) between the two groups. The rows of an image matrix represent ties sent from the row group to the column group. In the context of international trade, for example, the rows give the pattern of "exports," while the columns represent the pattern of "imports." Keeping with the example of trade, Table 1 represents a hypothetical situation in which actors are assigned to groups based on the similarity in their patterns of interaction with other actors in the network, and illustrates a latent core / periphery structure in four respects. First, the densest interaction occurs between actors in the core group, as indicated by a high value in the core-core cell of Table 1 . Second, the core group has the largest "reach" throughout the network as indicated by the core-group's large flows to and from the other two groups. Third, the periphery is isolated from itself as indicated by the zero value in the periphery-periphery cell in Table 1. Finally, the periphery is "dependent" on the core for both sending and receiving ties, as indicated by the fact that the periphery has only non-zero cells in both the core-periphery and periphery-core cells in Table 1. Evidence of some form of "unequal exchange" is also implied by the trade surplus of the core (e.g., exports are larger than imports) in

\footnotetext{
${ }^{3}$ The density of a set of relations refers to the ratio of ties that exist within a group to all possible ties within a group, while cohesion refers to the extent to which interaction is much more intensive within a group than between one group and another (Wasserman and Faust 1999: 101103, 267-270).
} 


\section{LOOKING BACK AND FORGING AHEAD 52}

their relations with both the semi-periphery and periphery, as indicated by the fact that the cells above the diagonal are larger than those below the diagonal.

What becomes evident at this point is that the core / periphery concept in world-systems analysis and that in social network analysis are distinct entities: where one is an approach to understanding how (among other things) various positions in the world-system cause divergent levels of accumulation over time, the other is a category of social structure defined by a specific type of interaction pattern. Despite these distinctions, a long-standing research tradition provides empirical confirmation of a number of critical world-system ideas by utilizing SNA techniques to operationalize various structural intuitions of world-system theory.

The logic behind the empirical operationalization of world-system structure with SNA methods can be summarized as follows: if there is, "in reality," an interconnected international division of labor in which "core" countries occupy dominant positions in the world economy, and peripheral and semi-peripheral countries occupy comparatively subordinate positions, then core actors in the international division of labor should be expected to have similar trade patterns visà-vis each other, but dissimilar trade patterns vis-à-vis peripheral or middling position countries (Arrighi and Drangel 1986; Hopkins and Wallerstein 1977, 1986). In short, patterns of trade between countries constitute a relational structure in which some positions - core positionsencourage relatively autonomous activity while others-peripheral positions-encourage constrained or dependent activity. Indeed, this structural intuition even predates the worldsystems perspective, and can be traced to early scholars such as Albert Hirschman ([1945] 1980) and Johan Galtung (1971). Given this understanding of the way in which cross-national relationships generate a social structure in which power, prestige and disadvantage vary by position in that structure, we will now trace the lineage of world-systems research using SNA techniques.

Early SNA studies focused on a method designed to identify the Roles and Positions of entities in a set of relational data (Wasserman and Faust 1994). At a conceptual level, the method starts with a relation (or set of relations) and (1) estimates the degree of similarity with an "equivalence criterion," (2) uses these estimates as the basis for assigning actors to relatively equivalent structural positions (either categorically, continuously, or both), and sometimes (3) determines the role of each equivalent group by analyzing the relations within and between equivalent groups (or "blocks" in the block model literature). This general approach has been treated extensively - both with reference to the world economy and with other substantive areas - in each of the "big three" generalist sociology journals: American Sociological Review (Mullins et al. 1977; Van Rossem 1996); American Journal of Sociology (Boorman and White 1976; White et al. 1976; Snyder and Kick 1979; Alderson and Beckfield 2004) and Social Forces (Anheier and Gerhards 1991; Smith and White 1992; Mahutga 2006).

One of the major methodological advancements in the SNA literature is the evolution of the equivalence criterion. Early SNA studies used structural equivalence as the criterion, which required two actors to have identical relationships to identical others, e.g., correlations of 1 on the row and columns of a socio-matrix. Later studies relaxed this requirement, allowing two actors to have identical relations with equivalent others. For example, despite a high degree of similarity on the patterns of exchange with other countries, the US and the UK would not be considered structurally equivalent because the US has ties to peripheral countries in Latin America, while the UK has ties to peripheral countries in Anglophone Africa. They share the same type of ties, for example, they may both exchange machinery for cocoa with peripheral countries, but they do not 


\section{JOURNAL OF WORLD-SYSTEMS RESEARCH}

meet the criteria of having the same ties to the same set of countries. This relaxation is called regular equivalence, and quantifies the extent to which two actors have similar relationships with equivalent others, rather than identical others. It is less restrictive and therefore a more general type of equivalence that (arguably) better captures the notion that core actors are equivalent by virtue of their similar relations to equivalent others (peripheral actors) (see Faust 1988; Borgatti and Everett 1992; Wasserman and Faust 1994). We will elaborate further on the particulars to this method following our overview of the world-systems literature using SNA techniques.

Table 2: Major Articles Reviewed

\begin{tabular}{|c|c|c|c|c|c|c|c|}
\hline Authors & Year & $\begin{array}{c}\text { Economic } \\
\text { and Non- } \\
\text { Economic } \\
\text { data? }\end{array}$ & $\begin{array}{c}\mathrm{C} / \mathrm{P} \\
\text { tructure? }\end{array}$ & $\begin{array}{c}\text { Zonal } \\
\text { Boundaries }\end{array}$ & $\begin{array}{l}\text { Discrete or } \\
\text { Continuous? }\end{array}$ & $\begin{array}{c}\text { Unequal } \\
\text { Exchange? }\end{array}$ & Other \\
\hline Snyder and Kick & 1979 & Yes & $\mathrm{X}$ & $\mathrm{X}$ & --- & --- & Growth \\
\hline Breiger & 1981 & No & $\mathrm{X}$ & --- & --- & --- & $\begin{array}{l}\text { Intra-core } \\
\text { competition }\end{array}$ \\
\hline Nemeth and Smith & 1985 & No & $\mathrm{X}$ & $\mathrm{X}$ & --- & $\mathrm{X}$ & Growth \\
\hline Smith and White & 1992 & No & $\mathrm{X}$ & $\mathrm{X}$ & $\mathrm{X}$ & $\mathrm{X}$ & Mobility \\
\hline Van Rossem & 1996 & Yes & $\mathrm{X}$ & $\mathrm{X}$ & $\mathrm{X}$ & --- & Growth \\
\hline Kick and Davis & 2001 & Yes & $\mathrm{X}$ & $\mathrm{X}$ & --- & --- & Growth \\
\hline Mahutga & 2006 & No & $\mathrm{X}$ & $\mathrm{X}$ & $\mathrm{X}$ & $\mathrm{X}$ & Mobility \\
\hline
\end{tabular}

Table 2 delineates four main categories of inquiry with which researchers use social network analysis to evaluate world-systems hypotheses within the general methodological framework of Roles and Positions. These include studies that (1) assess the extent to which crossnational relational data exhibit a core / periphery structure; (2) delineate boundaries between core, periphery and semi-periphery; (3) adjudicate between the core / periphery distinction as categorical or continuous; and (4) assess the hypothesis that some form of "unequal exchange" occurs across zones of the world-system. Several studies also combine one or more of these categories with an effort to assess levels of mobility and economic growth over time.

These four categories are nested within two approaches to the identification of worldsystem structure that differ with respect to the kind of relational data used. The first approach combines economic (total trade) with non-economic (treaty co-membership, military interventions, diplomatic exchanges) data (Snyder and Kick 1979). The second approach distinguishes between different types of commodity trade as the basis for analysis (Breiger 1981; 


\section{LOOKING BACK AND FORGING AHEAD 54}

Nemeth and Smith 1985). The remainder of this section will focus on the empirical worldsystems literature that uses social network analysis and follows one of these two data collection approaches. The literature is organized chronologically within each of these two approaches in order to illustrate the evolution of the field.

We begin with the classic network study of the world-system by Snyder and Kick (1979). The article was largely confined to the first and second categories above-delineating the existence of a core / periphery world-system and the boundaries between the core, periphery and semi-periphery. Snyder and Kick were also the first to assess whether or not occupying a high position in the core / periphery hierarchy actually did predict higher growth, as opposed to simply showing that countries that manifested some form of "dependency" had slower than average growth. Using data on four types of global relationships (trade, military interventions, diplomatic exchanges and treaty memberships) collected between 1960 and 1967, they applied a structural equivalence algorithm - CONCOR (Breiger et al. 1975; White et al., 1976) - as their equivalence criterion. Of these four types of relationships, they found the hypothesized core / periphery interaction pattern to be evident primarily in the trade relationships. The authors made two other contributions. First, they argued for greater nuance in the periphery and semi-periphery categories, depicting three partitions within the semi-periphery and six smaller partitions in the periphery. Second, using OLS regressions, they found a difference in growth rates between categories, noting that the core group grew consistently faster than lower tier groups in the years studied (1955 to 1970). ${ }^{4}$ In a follow-up study, Kick and Davis (2001) used a structural equivalence analysis, which confirmed that the core was comprised of Western industrial countries, and that they dominated the world system in economic, transportation, communications, sociocultural, political and military networks. They concluded that the strength of international economic ties impacted domestic (national) economies and trajectories of overall economic growth and well-being (Kick and Davis 2001:1570-1573).

Van Rossem (1996) also combined economic and non-economic relationships, including imports, exports, arms trade, diplomatic exchange and presence of foreign troops as the basis for his analysis. He used a novel methodology - a role equivalency measure based on the triad census - to "test the world-system paradigm as a general theory of development," (Van Rossem 1996: 508), and to address the question of whether or not the core / periphery hierarchy is best conceptualized as categorical or continuous. Van Rossem's findings with respect to the first two categories in Table 2-assessing whether or not the network conforms to a core / periphery structure and assigning countries to groups - was largely consistent with previous studies, except he placed China, Brazil, Saudi Arabia and the Soviet Union in the core (using 1983 trade data). Unlike previous work, however, Van Rossem found that world-system position had no direct effect on economic growth, challenging expectations of world-systems analysis. Finally, Van Rossem's secondary analysis suggests that "coreness" in the world-system is much more continuous than categorical, and that there are "large differences in power among core countries"

\footnotetext{
${ }^{4}$ Snyder and Kick's (1979) assignment of countries to positions in the world-system and various amendments by Bollen (1983) and Bollen and Appold (1993) has been the basis for a large number of empirical studies in which world-system position is an independent variable on which dependent variables such as income inequality (Alderson and Nielsen 1999), world-city position (Alderson and Beckfield 2004), IGO and INGO memberships (Beckfield 2003), urbanization (London 1987), democracy (Wejnert 2005), and others are regressed.
} 


\section{JOURNAL OF WORLD-SYSTEMS RESEARCH}

(Van Rossem 1996:518), an argument that is consistent with the world-systems literature on hegemonic cycles (e.g. Arrighi 1994; Chase-Dunn 1998).

In summary, the work of Snyder and Kick (1979) and those in its lineage are similar with respect to (1) incorporating both economic and non-economic data; (2) a particular focus on categories 1 and 2 from Table 2, by testing for a core / periphery structure and delineating the boundaries between zones of the world-system; and (3) using the results of network analysis as independent variables to explain subsequent growth. The major difference rests primarily with the work of Van Rossem (1996) who (1) uses a less stringent equivalence criterion-"role equivalence;" (2) estimates growth regressions that largely contradict the hypothesis that worldsystem position should have a significantly positive direct effect on economic growth; and (3) asks the additional question of whether or not the core / periphery structure he identifies is categorical or continuous.

The second broad approach begins with Breiger (1981) and is further developed by Nemeth and Smith (1985), Smith and White (1992) and Mahutga (2006). These authors also address categories 1 and 2 from Table 2, but they differ from the Snyder and Kick lineage in two ways. First, they base their analysis solely on economic data in the form of commodities that are roughly classified according to their levels of industrial "sophistication." Second, they add a third and fourth category that focuses on the continuous vs. categorical nature of the world-system and attempt to operationalize the notion of unequal exchange. In what follows, we review the works of Breiger (1981), Nemeth and Smith (1985), Smith and White (1992) and Mahutga (2006), the most recent work in the lineage. Following the review we will summarize the similarities / differences between this lineage and that of Snyder and Kick (1979), as well as the evolution of the field as a whole.

Chronologically, the first piece is that of Breiger (1981). Although Breiger restricted his focus to relatively wealthy developed countries of the Organization for Economic Cooperation and Development (OECD), his goal was to connect a more general social structural approach to international trade and the typical approach still prevalent in economics. The latter approach views trade between two countries as the linear function of individual attributes, such as GDP and population, and geographical distances from potential partners (e.g. Feenstra et al. 2001). Breiger used an identical analytic strategy to that of Snyder and Kick (1979), e.g., a structural equivalence criterion with the CONCOR program to analyze four types of trade relationships (Agricultural Products, Raw Materials, Manufactured Goods and Energy Resources). He found that even the OECD countries in his investigation engaged in a core / periphery interaction pattern among themselves across all four types of commodities. He also found "multiple competing centers" after adjusting for each country's overall volume of trade (Breiger 1981:375).

Following Breiger (1981), Nemeth and Smith's (1985) attempted to differentiate core, semi-periphery and periphery relations based on patterns of trade in commodities that embody different forms of industrial sophistication or capital intensity at a more specific level of aggregation than Breiger. Using CONCOR, they located a "strong" and "weak" semi-periphery, creating four distinct categories of trade relations. They also operationalized the notion of unequal exchange, and thereby discovered variation in interaction patterns across different commodity types and zones of the world-system (Nemeth and Smith 1985:544). ${ }^{5}$ Using regression analyses,

\footnotetext{
${ }^{4}$ Another major contribution made by Nemeth and Smith (1985), and subsequently Smith and Nemeth (1988), was an attempt to categorize commodities based on the pattern of exchange in the
} 
they demonstrated that the core had significantly higher wealth and lower child mortality than the weak semi-periphery and the periphery, and higher energy consumption, wealth generation and energy consumption than all lower blocks. They did not find significant differences between the core and lower blocks with respect to economic growth in percentage terms and in levels of within country inequality, however.

Smith and White (1992) built on these findings by 1) introducing a more general measure of equivalence-regular equivalence; 2) testing the theory of unequal exchange; and 3) conducting the first analysis of world-system mobility. The regular equivalence algorithm produced a matrix that assigned a level of equivalence between each actor that ranged from 0 to 1. This matrix served as the basis for subsequent analyses in which they were able to create both a continuous scaling - with a correspondence analysis of the equivalencies - as well as a 5 position block model by analyzing the equivalence matrix with a hierarchical clustering routine (Borgatti 1994). They identified five positions - core, strong semi-periphery, weak semi-periphery, strong periphery and a weak periphery - that corresponded to an increasing level of dissimilar trade patterns vis-à-vis the core. They were also the first to find empirical support for the notion that the structure of world trade was more fundamentally continuous rather than categorical.

In addition to the methodological contribution of regular equivalence, Smith and White provided stronger evidence of unequal exchange by showing that countries in higher zones of the world-system produced and exchanged sophisticated capital intensive manufactured goods for raw materials and labor intensive goods produced in lower zones (1992:880-882). Finally, Smith and White were the first to empirically examine the issue of mobility in the world-system. Using world trade data from 1965 and 1980, they found evidence of "much more upward than downward mobility" (Smith and White 1992:880). The reasons for the mobility were speculated upon but the question was left for future research.

Mahutga (2006) provided the most recent contribution in the lineage of Breiger (1981) and Nemeth and Smith (1985). He used an analytic strategy similar to that of Smith and White (1992) to evaluate how hypothesized structural changes associated with globalization and the new international division of labor (NIDL) affected inequality in the structure of the world economy in the period spanning four and half decades (1965 to 2000). He advanced this line of methodological by quantifying the fit of a core / periphery model to the data, levels of asymmetric commodity flow, and mobility - as well as temporal variation in these types of changes. His findings challenged some claims in the globalization literature of decreasing inequality by demonstrating that the core / periphery interaction pattern remained intact through 2000 , that commodity exchanges across zones of the world-system remain unequal, and that the globalization era (1980-2000 - or more recent wave) was associated with less structural change than the prior period (1965-1980) despite evidence of significant upward mobility of a small number of countries.

Our review identifies two discernable lineages with respect to network studies of the world-system: those beginning with Snyder and Kick (1979), and those beginning with Breiger (1981) and Nemeth and Smith (1985). The major differences between the two types are 1) the types of data used for their analyses - the former using both economic and non-economic

world economy. In short, a factor analysis revealed 5 "bundles" of goods that had similar flow patterns and were interpretable along a hierarchical processing continuum from food products to heavy manufacturers / high technology. 


\section{JOURNAL OF WORLD-SYSTEMS RESEARCH}

relations while that latter use multiple commodity types, and 2) how they address the mechanism of "unequal exchange" and mobility. The major similarities between the two types are 1) they follow the general SNA methodological approach of Roles and Positions; 2) they address categories 1, 2 and 3 in Table 2-testing for the presence / absence of a core / periphery structure, delineating boundaries between zones of the world-system, and trying to assess whether or not the structure of the world-system is best conceptualized as categorical or continuous; and 3) a general evolution away from structural equivalence toward less restrictive and more general definitions of equivalence such as regular and role equivalence (Kick and Davis 2001).

There are also a number of studies that utilize network analytic techniques to answer questions of interest to those studying world-systems issues, but do not necessarily follow the lineage we discuss above. Among this research are those that study the structure of the world-city system (Alderson and Beckfield 2004; Smith and Timberlake 2001; Taylor 2004) ${ }^{6}$, the formation of other structural properties in international trade such as trading blocks (Su and Clawson 1994; Blanton 1999b), regionalization (Kim and Shin 2002) and alternative conceptualizations of the structure of the world economy (Blanton 1999a; Kim and Shin 2002). While this is not an exhaustive list, it is suggestive of the many possibilities for using social network methodology to pursue questions that are important to world-systems research.

\section{ANALYZING RELATIONAL DATA: A DEMONSTRATION OF CLASSIC AND RECENT APPROACHES}

In the previous section, we outlined the intellectual lineage of social network analyses of the world-system that began with the classic work of Snyder and Kick (1979). A major motivation of this article, however, is to give the reader a basic sense of the analyses that are involved in this tradition in order to encourage future research. Space limitations preclude an exhaustive treatment of possible methodological applications to the study of the world-system, so we focus instead on the general approach taken in the classic lineage of the literature - the analysis of Roles and Positions, as well as introducing a recent variant - the Exponential Distance Model (EDM) that bears a relationship to some older techniques that have not made their way into world-systems research.

We begin with a brief introduction to relational data. Understanding relational data becomes easier by way of comparison to the type of data that is more commonly used in the social sciences - attributional data. Relational data are, as the name would suggest, data that measure the presence, absence or strength of a tie on some relationship - be it trade, investment, military interventions, etc.- - between at least two actors. Attribute data, on the other hand, is data that is collected at the level of one individual that captures their relative level of an attributeGDP per capita, foreign investment stock, economic growth, income inequality, etc. Thus, where relational data captures a relationship between at least two actors, attribute data captures the characteristics of individuals.

\footnotetext{
${ }^{6}$ Peter Taylor is associated with a fairly large community of scholars interested in questions about the world-city system. For an overview, see http://www.lboro.ac.uk/gawc/.
} 
Because social network data is relational, social network analysis is almost uniformly interested in describing and / or predicting the latent structure of a set of relationships. Analysis of attribute data, on the other hand, is almost uniformly interested in describing and / or predicting the pattern of association between levels of attributional covariates. The theoretical underpinnings of most attributional approaches in the social science, however, tend to assume that attributional covariates reflect the outcome of an underlying structural dynamic-i.e. a high value in foreign capital penetration is an indicator of occupying a "dependent" position vis-à-vis some other country in the world-system. Indeed, much has been written as to the strengths of relational data vis-à-vis attribute data, but no where more eloquently than in White and Breiger (1975:68), where they state that, attribute data

measure select consequences of structural pattern (of the actual ties among individuals or organizations); they are useful indicators of questions to be asked by analyzing social structure directly, but they are neither descriptions nor analyses of the structure itself. (also in Breiger 1981:357)

This is not to say that relational data are intrinsically better than attribute data, only to note that if faced with a relational theory, i.e. that a country's position in the world system is defined by their relationships to others, relational data and network analysis provide a direct research strategy with which to uncover the structure of relationships between actors (Chase-Dunn and Grimes 1995; Hopkins 1978; Wallerstein 1974).

As described above, the network analyses utilized in studying the world-system share a common analytical framework that is driven by a desire to understand the structure of the worldsystem, which makes it possible to understand how this structure does or does not impact many outcomes for individual nation-states within the structure. The general approach taken in the current social network analysis-world-systems theory literature is called Network Positions and Roles in the standard reference book for social network analysis (Wasserman and Faust 1994: 347-393; 461-502; also see Doreian et al. 2005). According to this text,

There are two key aspects to the positional and role analysis of social networks: identifying social positions as collections of actors who are similar in their ties with others, and modeling social roles as systems of ties between actors or between positions. (Wasserman and Faust 1994:351)

Practically, the research process involves 1) measuring the similarity between actors with a formal definition of equivalence (i.e. structural, regular, etc.), 2) grouping similar actors into mutually exclusive positions in such a way that inter-group similarity is minimized, and 3) understanding (modeling) the ways in which the various positions interact with each other to understand their various roles in the network.

We illustrate this procedure by providing a detailed position and role analysis of a new data set of world trade data. At each step in the process we will discuss choices that must be made before moving onto the next step, as well as compare and contrast the research strategy adopted by the papers reviewed earlier. We begin with a discussion of the data used for this analysis. 


\section{JOURNAL OF WORLD-SYSTEMS RESEARCH}

\section{Trade Data}

The primary dataset used for this study comes from the World Trade Analyzer (WTA) (Statistics Canada 2008). The data represent total trade between country pairs in $1980(\mathrm{~N}=164)$ and 2001 $(\mathrm{N}=181)$, respectively. Countries included in the analyses are reported in Appendix A. Countries report their exports and imports to the United Nations using various commodity classification schemes and with varying levels of detail. Statistics Canada then organizes the data. They begin with reported trade as the base data, estimate missing values through mirror statistics, and, wherever possible, distribute highly aggregated regions or commodity categories to more detailed countries or categories. The end product is a non-symmetrical, square matrix for each year. While our analysis focuses on total trade, data are also available according to the classification scheme SITC rev. 2. Current versions of WTA contain data from 1985 to 2003. The version released in 2001 included data from 1980 to 1999; earlier versions also included data beginning with $1980 .^{7}$

\section{Role and Position Analysis}

Figure 1 depicts the three stages in the role and position analysis we carry out here. In the first stage, a researcher chooses a measure of equivalence with which to gauge the level of similarity between each country based on their patterns of trade with others. The measure we use is regular equivalence, which is available in UCINET (see Borgatti, Everett, and Freeman 2002). ${ }^{8}$ We noted in the review above that structural equivalence, and particularly the CONCOR program, was the measure of similarity used in Snyder and Kick (1979), Breiger (1981), Nemeth and Smith (1985) and Kick and Davis (2001). CONCOR was a top of the line technology in 1979, but has since been shown to be a less optimal strategy than some other approaches because of the fact that it is an iterative program that by design produces an equal number of groups. CONCOR begins by splitting a data matrix into two groups, which are each then split into two more groups, and so on, until no further partitions are made. The resulting large and even number of groups is somewhat artifactual (Wasserman and Faust 1994:375-381). A better approach to determine structural (rather than regular) equivalence might be to simply correlate the rows and columns of the data

${ }^{7}$ The UN does not report data for Taiwan for political reasons (e.g. China's "One Nation" policy), and often the data for China includes Taiwan's information. The UN Comtrade database incorporates Taiwan as a trading partner by adding it to "Other Asia, not elsewhere specified" (code 490) which could in principle contain trade other than from Taiwan but is generally considered Taiwan. In general, using reporter data to represent Taiwanese trade reasonably matches the data actually reported by Taiwan (although never a perfect match). WTA is presumed to use the Comtrade data directly and to not supplement it with OECD data. Hong Kong re-exports are another problematic reporting area. These issues reflect a need for the ITRB to compile a sifted, documented and transparent set of estimates. Taiwan's reported data is therefore not included in Comtrade; data for Taiwan in the WTA is taken from other countries' reported trade with Taiwan (e.g., "mirror flows"). We thank Ronald Jansen, UN Statistics division, and Scudder Smith, WTA, for their help in answering the questions related to preparing the data for analysis.

${ }^{8}$ The original trade matrices were transformed with the base 10 logarithm to reduce skew. 
matrix, and then proceed with the rest of the steps outlined in figure 1 (Breiger 1981; Wasserman and Faust 1994:368-9).

\section{Figure 1: Analytic Strategy for Role and Position Analyses}

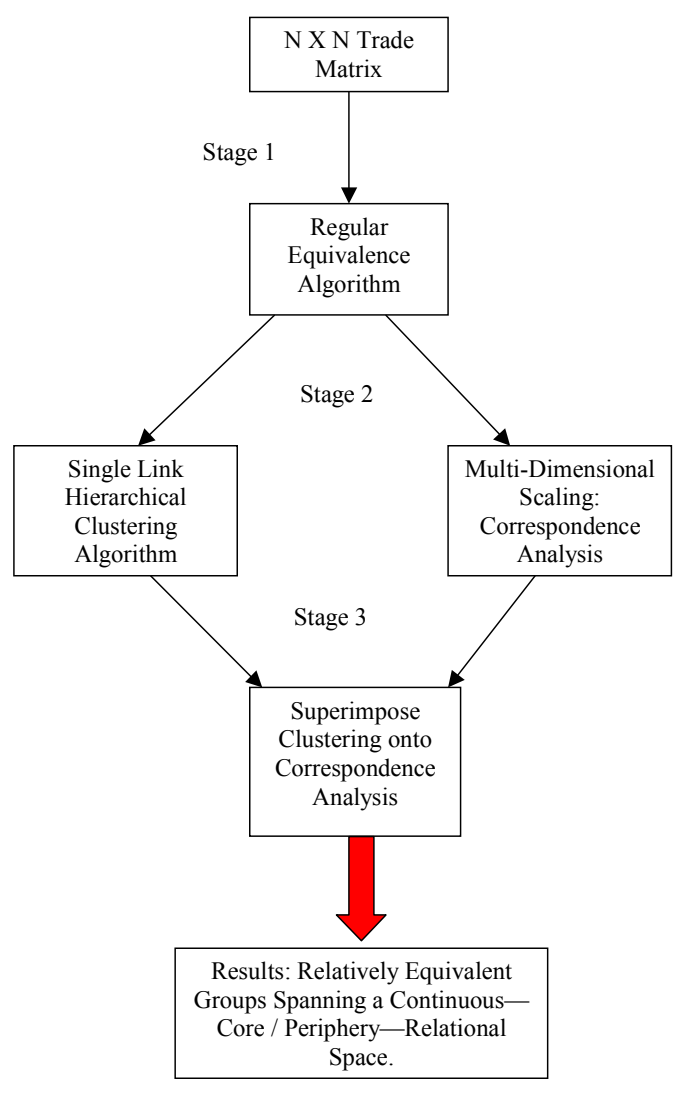

We begin this process by calculating the degree of regular equivalence for each pair of countries with the following algorithm (White and Reitz 1985). The regular equivalence $\left(M_{i j}^{t+1}\right)$ between countries $i$ and $j$ at iteration $\mathrm{t}+1$ is:

$$
M_{i j}^{t+1}=\frac{\sum_{k=1}^{g} \max _{m=1}^{g} \sum_{r=1}^{R} M_{k m}^{t}\left({ }_{i j r} M_{k m r}^{t}+{ }_{j i r} M_{k m r}^{t}\right)}{\sum_{k=1}^{g} \max _{m}^{*} \sum_{r=1}^{R}\left({ }_{i j r} \operatorname{Max}_{k m r}+{ }_{j i r} \operatorname{Max}_{k m r}\right)}
$$

where the denominator is the maximum possible value of the matches between the profiles of $i k$ and $j m$ that would occur if all of the ties between $i$ and its alters $(k)$ were perfectly matched to the ties between $j$ and its alters $(m)$, and all of $k$ and $m$ were regularly equivalent. The numerator 


\section{JOURNAL OF WORLD-SYSTEMS RESEARCH}

determines the best matching of the ties between $j$ and $m$ for $i$ 's ties to $k$ weighted by the regular equivalence of $k$ and $m$ from the previous iteration (Wasserman and Faust, 1994). Thus, the algorithm determines the best possible matching of ties between $i$ and $j$ weighted by the equivalence of their alters, and divides that value by the maximum possible value of the numerator. It is important to remember that the equivalence of each pair of actors is revised after each iteration $(t+1)$. We have specified three iterations, with the third serving as the measure of regular equivalence for each pair of countries. It is highly unlikely that any two nations would be exactly equivalent, so we apply a regular equivalence algorithm to the matrices of trade data. This produces an equivalence matrix in which the $i j$ cell equals the regular equivalence between $i$ and $j$ designating maximally dissimilar as (0) and regularly equivalent as (1).

Although the analysis conducted here is limited to one type of relationship - total tradeboth the method proposed here and the general approach of social network roles and positions is easily generalized to multiple relations. These relations may be economic or non-economic relations as in Snyder and Kick (1979), disaggregated commodity trade used by Nemeth and Smith (1985), or any other type of relationship. In short, when multiple relations are desired, you simply create a "super matrix" by stacking each relationship on top of one another before applying the equivalence criterion. The resulting equivalence matrix would then represent the equivalence between each country after taking into account the similarity / dissimilarity across all the relationships (see Romney, Moore and Brazill 1998 for a discussion of stacking in the context of correspondence analysis).

Given the equivalence matrix we derive in stage one, stage two involves methods to reduce the dimensionality of the cross-country equivalencies, both categorically and continuously. The analysis here uses the matrix of regular equivalencies as input for both a single link hierarchical clustering routine and correspondence analysis for each year. Because the matrix of regular equivalencies gives a measure of equivalence between each pair of actors, the hierarchical clustering routine is well suited to finding "cut points" that minimize the between group variance in regular equivalence (or maximize the within group similarity). Hierarchical clustering starts by (1) putting each actor in an $\mathrm{N} \mathrm{x} \mathrm{N}$ matrix into its own cluster so that the similarity between clusters equals the similarity between each actor. The procedure then (2) finds the most similar pair of actors and merges them into one cluster. Next (3), we compute similarities between the new cluster and each of the other actors. The process (4) continues with the second and third steps until all actors have been merged into a single cluster of size $\mathrm{N}$ (Borgatti 1994). ${ }^{9}$ In principle, an analyst could start out with some $\alpha$ criterion whereby actors $i$

9 Single link hierarchical clustering is one choice among three common approaches to hierarchical clustering - single link, complete link and average link. The single link routine defines the similarity between each cluster as the greatest similarity from any member of one cluster to any member of the other cluster. The complete link routine defines the similarity between one cluster and another as the smallest similarity from any member of one cluster to any member of the other cluster. The average link routine defines the similarity between one cluster and another cluster to be equal to the average similarity from any member of one cluster to any member of the other cluster. Some research has shown that the complete link routine may be less subject to "chaining," whereby a large group results from the trivial successive additions of a single actor, and some argue that the average approach is the least likely to produce trivial results (see Wasserman and Faust 1999: 381, Krackhardt 1999). As a practical strategy, it is worth 
and $j$ would be considered regularly equivalent if $\mathrm{RE}_{\mathrm{ij}} \geq \alpha$. There is no a-priori theory, however, that favors one level of alpha over another, and large real world data sets are rarely broken down into discrete homogenous groups at any single threshold level. Our approach is to use the hierarchical clustering results in conjunction with correspondence analysis to determine the boundaries of each equivalence group.

Correspondence Analysis is one of a family of techniques that draw on a common computational foundation: the Singular Value Decomposition (SVD), and is widely available in statistical packages such as UCINET, Stata and Statnet. ${ }^{10}$ At a conceptual level, correspondence analysis represents the basic structure in a set of data by decomposing a matrix into its three component parts: a matrix $\mathbf{U}$ that summarizes the information in the rows; a matrix $\mathbf{V}$ that summarizes the information in the columns, and a diagonal matrix of singular values $\mathbf{d}$ that weights each $\mathbf{U V}$ vector by its importance to the overall structure. Thus, the size of the singular values in $\mathbf{d}$ that correspond to $\mathbf{U}$ and $\mathbf{V}$ indicates how much variation is explained by each dimension (Weller and Romney 1990). Correspondence analysis routines are widely available (UCINET, Stata, SPSS, and R, for example, all contain implementations of correspondence analysis). A classic correspondence analysis consists of four steps that we explain here, but which are automated in standard computer packages.

The first step generates matrix $\mathbf{H}$, in which the cells of the original matrix have been transformed so that the row / column marginals are approximately 1, with the following equation:

$$
h_{i j}=f_{i j} / \sqrt{f_{i} \cdot f_{j}} \text {, }
$$

where $h_{i j}$ is the transformed value in $\mathbf{H}, f_{i j}$ is the original value in the $i j^{\text {th }}$ cell of the regular equivalence matrix, $f_{i}$. is the row marginal, and $f_{j}$. is the column marginal. This step removes the effect of the row / column totals before performing the second step of SVD.

The third step in a classic correspondence analysis rescales the information in $\mathbf{U}$ and $\mathbf{V}$ to obtain "optimal" or "canonical" scores by multiplying both $\mathbf{U}$ and $\mathbf{V}$ by the square root of the ratio of the total marginals to the row / column marginals, respectively:

$$
X_{i}=U_{i} \sqrt{f . . / f i .} \text { and } Y_{i}=V_{j} \sqrt{f . . / f . j}
$$

The final step incorporates the singular value "weights" so that each dimension of $\mathbf{X}$ and $\mathbf{Y}$ is multiplied by the square root of its respective singular value, such that the size of each dimension of $\mathbf{X}$ and $\mathbf{Y}$ corresponds to the amount of variance explained by each.

investigating all three approaches to see if the resulting clusters are "robust" across the three approaches.

${ }^{10}$ All of the positional / role analyses (i.e. all but the exponential distance model) were carried out with UCINET. We use UCINET because it is very user friendly, and we can reasonably expect a shallow learning curve for the novice. Pajek is also recommended, and has an excellent graphing function (see De Nooy, Wouter, Mrvar, and Batagelj 2005). The SNA package for R has multiple functions and is very versatile but requires the user learn R. For an excellent overview, see http://erzuli.ss.uci.edu/R.stuff. 


\section{JOURNAL OF WORLD-SYSTEMS RESEARCH}

In sum, correspondence analysis begins by generating $\mathbf{H}$, which is a transformation of the original matrix (in this case, a matrix of regular equivalencies) so that the marginals (or expected values) are removed. It then performs a singular value decomposition on $\mathbf{H}$ to produce three matrices, $\mathbf{U V}$ and $\mathbf{d}$. As a third step, correspondence analysis rescales $\mathbf{U}$ and $\mathbf{V}$ with equation 3 to produce the $\mathbf{X}$ and $\mathbf{Y}$ matrices. Finally, correspondence weights each $\mathbf{X}$ and $\mathbf{Y}$ dimension by their associated singular values to produce a multidimensional representation of the similarity between actors (in this case country regular equivalencies) in which each orthogonal dimension is successively "less important" to the overall structure. ${ }^{11}$

These results can be easily visualized by plotting successive dimensions of either $\mathbf{X}$ or $\mathbf{Y}$, or $\mathbf{X}$ and $\mathbf{Y}$. Thus, correspondence analysis allows us to represent actors in a multi-dimensional Euclidian space by assigning coordinates (weighted dimensions of $\mathbf{X}$ and $\mathbf{Y}$ ) to actors that place them close to those with whom they are similar and far from those with whom they are dissimilar (Weller and Romney 1990). Because our matrix of regular equivalencies is symmetric, e.g., $\mathbf{X}=$ $\mathbf{Y}$, we can simply plot dimensions from one or the other and the distance between each point in the graph corresponds to the dissimilarity between their equivalencies with the whole network. One can then evaluate the "fit" between single or multiple dimensions with the following equation:

$$
100 \times \frac{\lambda_{\mathrm{m}}^{2}}{\sum_{\mathrm{m}=1}^{\mathrm{M}} \lambda_{\mathrm{m}}^{2}},
$$

where $M$ is Singular Value 1, 2, 3, ..M. Interpreting the results from correspondence analysis depends on the amount of variation explained by each singular value/dimension and the observed spatial pattern of objects in the Euclidian space. Thus, one can have a relatively simple structure (few significant dimensions) or a complex one (many significant dimensions) and proximate actors in the Euclidian space have similar relational patterns.

The final stage of our Role and Position analysis brings the results of the two complementary procedures - hierarchical clustering and correspondence analysis - together to derive a set of positions to describe the structure. This stage can be broken down into three steps. In the first step, we examine the hierarchical clustering results in the form of a dendrogram to give a first approximation of the groups from that analysis. A dendrogram is a visualization of the hierarchical clustering process described above, in which each step in the process is represented by the fusion of two or more actors into the same cluster. Dendrograms typically display each actor separately at the bottom, and the range of the equivalence criterion on a vertical axis where the values range from high to low as you read from bottom to top, terminating at the top when all actors are merged into a single group. Clearly, the bottom most clustering (every actor in a separate group) and the top most clustering (every actor in the same group) are trivial and uninteresting. Thus, "the 'trick' is to choose the point along the series that gives a useful and interpretable partition of actors into groups (Wasserman and Faust 1994: 383).

The second step displays the first and second dimensions of the CA results in the form of a scatterplot, and superimposes the first approximation of the HC results on top so that actors in the same group are the same color and / or shape. The final step of this procedure seeks

${ }^{11}$ The reader should note that the first dimension of $\mathrm{U}$ and $\mathrm{V}$, and the first singular value in $\mathrm{d}$ are considered trivial since they will always equal 1, by construction (see equation 2 above). 
consistency between the correspondence analysis results and the hierarchical clustering results. The consistency should be high if the HC results are meaningful, and the final stage should consist of nothing more than minor changes in group assignments at the group boundaries depicted in the second stage. Because the hierarchical clustering procedure can be derived in several ways and therefore vary, while the CA results are always consistent, we rely on the blocks for which the CA analysis is most consistent.

In the next section, we apply recent advances in correspondence analysis (CA), referred to as the Exponential Distance Model (EDM), to the same data set. CA has many variants and derivations. It can be used both as an exploratory technique and as a method of fitting a statistical model. This approach corresponds to multiple correspondence analysis (MCA) or attribute seriation (LeBlanc, 1975; Duff 1996) and is incorporated in the R package homals (De Leeuw and Mair 2008). EDM represents the maximum likelihood fitting as opposed to the least squares fitting of CA models. The EDM is a data reduction and data representation method which shifts CA from multivariate exploration to model testing.

Exponential Distance Model:

This analysis also begins with a square matrix $\mathrm{F}$, where the rows and columns of the table correspond with the number of countries in the study. Cell $\mathrm{f}_{\mathrm{ij}}$ of the table indicates how much country $i$ exports to country $j$, or, equivalently, how much country $j$ imports from country $i$. The diagonal of the table usually consists of missing data, because countries do not import from or export to themselves. Thus, using terminology from Haberman (1974) and Bishop et al. (1975), the diagonal of the table has structural zeroes. The next step is to create our model. We start with the assumption that the $\mathrm{f}_{\mathrm{ij}}$ are realizations of independent Poisson variables $\underline{\mathrm{f}}_{i j}$, with $E\left(\underline{f}_{i j}\right)=\lambda_{i j}$.

It is well known that by conditioning on the row marginals this model also covers the product multinomial model, in which rows are independent multinomials. The negative log likelihood for the Poisson model is

$$
\Delta=\sum \sum\left\{\lambda_{i j}-f_{i j} \log \lambda_{i j} \mid i \neq j\right\}
$$

The assumption of independent Poisson cells is made for convenience, for the same reasons the assumption of normality is made in continuous multivariate analysis. Alternatively, one can simply think of (5) as a natural way to measure the distance between the observed frequencies $f_{i j}$ and the expected frequencies $\lambda_{\mathrm{ij}}$.

Base Models:

The two key specifications that we shall elaborate on in this paper are the quasi-independence model and the quasi-symmetry model. The quasi-independence model says that

$$
\lambda_{i j}=\alpha_{i} \beta_{j} \quad \forall i \neq j
$$

where $\alpha_{i}$ is a row (export) parameter and $\beta_{j}$ is a column (import) parameter.

The quasi-symmetry model says

$$
\text { (6b) } \lambda_{i j}=\alpha_{i} \beta_{j} \eta_{i j} \quad \forall i \neq j
$$




\section{JOURNAL OF WORLD-SYSTEMS RESEARCH}

where $\alpha_{i}$ and $\beta_{j}$ are the same as above, and $\eta_{i j}=\eta_{j i}$. The $\eta_{j i}$ are called similarities. Clearly quasi-independence is the special case of quasi-symmetry in which all similarities are equal. In the quasi-independence model, each country has an export effect $\alpha_{i}$ and an import effect $\beta_{j}$, and the amount of trade between countries is just determined by these export and import values.

In the quasi-symmetry model the trade is determined by both export and import values and the similarity. Both the quasi-symmetric and the quasi-independence model are base models, in the sense that we do not expect them to be even approximately true but we can use them as baselines with which to compare our hopefully more realistic models.

Geometric Models:

We can restrict the quasi-symmetry models further by requiring that the similarities are inversely related to distances on an unknown map. In particular we assume the quadratic Euclidean model:

$$
\eta_{i j}=\exp \left\{-\sum_{s=1}^{p}\left(x_{i s}-x_{j s}\right)^{2}\right\}
$$

The problem is now to recover the map, along with the import and export values of the countries. Alternatively, our software can also fit the simple Euclidean model:

$$
\eta_{i j}=\exp \left\{-\sqrt{\sum_{s=1}^{p}\left(x_{i S}-x_{j S}\right)^{2}}\right\}
$$

but for various reasons we will initially concentrate on the quadratic case in this paper. Geometric models of the form (7a) or (7b) have been proposed many times, and in many different contexts, in econometrics, psychometrics, and sociometrics.

\section{Correspondence Analysis Approximation:}

Let us look more closely at the quadratic Euclidean model. By expanding the squared distance we

have

$$
\eta_{i j}=\exp \left\{-\sum_{s=1}^{p} x_{i s}^{2}\right\} \exp \left\{-\sum_{s=1}^{p} x_{j s}^{2}\right\} \exp \left\{+2 \sum_{s=1}^{p} x_{i s} x_{j s}\right\}
$$

If we define

$$
\begin{aligned}
& \bar{\alpha}_{i}=\alpha_{i} \exp \left\{-\sum_{s=1}^{p} x_{i s}^{2}\right\}, \\
& \bar{\beta}_{j}=\beta_{j} \exp \left\{-\sum_{s=1}^{p} x_{j s}^{2}\right\},
\end{aligned}
$$

and $\bar{x}_{i s}=\sqrt{2} x_{i s}$ then for the squared Euclidean model

$$
\lambda_{i j}=\mu \alpha_{i} \beta_{j} \exp \left\{-\sum_{s=1}^{p}\left(x_{i s}-x_{j s}\right)^{2}\right\}=\mu \bar{\alpha}_{i} \bar{\beta}_{j} \exp \left\{\sum_{s=1}^{p} \bar{x}_{i s} \bar{x}_{j s}\right\}
$$


which says that the squared Euclidean model is equivalent to the inner product model. Instead of fitting exponents of negative squared distances, we could also fit exponents of inner products, and obtain basically the same results (with an exactly equal goodness-of-fit. For the next step in the approximation, observe that if $\mathrm{z}$ is small, then $\exp (\mathrm{z}) \approx 1+\mathrm{z}$.

Thus if the inner products are small, then

$$
\lambda_{i j} \approx \mu \bar{\alpha}_{i} \bar{\beta}_{j}\left\{1+\sum_{s=1}^{p} \bar{x}_{i s} \bar{x}_{j s}\right\}
$$

and this is the model used in the symmetric version of Correspondence Analysis (if you interpret Correspondence Analysis as a model fitting technique). In ordinary Correspondence Analysis one computes separate maps for rows and columns, which means that the squared Euclidean distance model is approximated by a Correspondence Analysis model with row and column scores equal. These approximations are also discussed in detail by Goodman (1991).

Note, that in both CA and EDM, we suppose that the frequency of interaction between row actors $i$ and column actor $j$ is a function of marginal effects and degree of similarity or degree of attraction between the actors. In other words, we draw a map of the actors such that distance in the map translates inversely to the degree of similarity--proximate actors are similar, and distant actors are dissimilar. In CA we use least squares techniques to fit the model, and in EDM we use maximum likelihood techniques, which are guaranteed to produce optimal estimates of the model. Fitting:

Fitting the model means maximizing the Poisson likelihood. We have constructed convergent iterative algorithms, with corresponding computer implementations in the $\mathrm{R}$ programming language, based on the majorization principle (e.g. De Leeuw 1994). We shall not give the details of the algorithm here, but it amounts to solving a sequence of multidimensional scaling problems on transformed data. ${ }^{12}$

\section{RESULTS}

\section{Results from Role and Position Analysis}

The common question asked across the studies reviewed in Table 2 is does the network conform to a core / periphery structure. All of the studies we reviewed found this to be the case. Therefore, we expect that networks of trade will conform to a core / periphery structure in the present analysis. Figures 2 (1980) and 3 (2001) depict the first and second dimension from the correspondence analysis of regular equivalence, with the results of our hierarchical clustering routine superimposed on top. Due to the high number of actors, we do not include labels in these graphs, but tables A1a through A2b in the Appendix provide the information on the position of each country. The origin of the Euclidean space (the point on the graph where the $\mathrm{x}$ and $\mathrm{y}$ axis are 0 ) from our correspondence analysis reflects the average regular equivalence profile in the network.

${ }^{12}$ Code is available from the authors. 


\section{JOURNAL OF WORLD-SYSTEMS RESEARCH}

Figure 2: Correspondence Analysis of Regular Equivalence with Hierarchical Clustering Superimposed, 1980

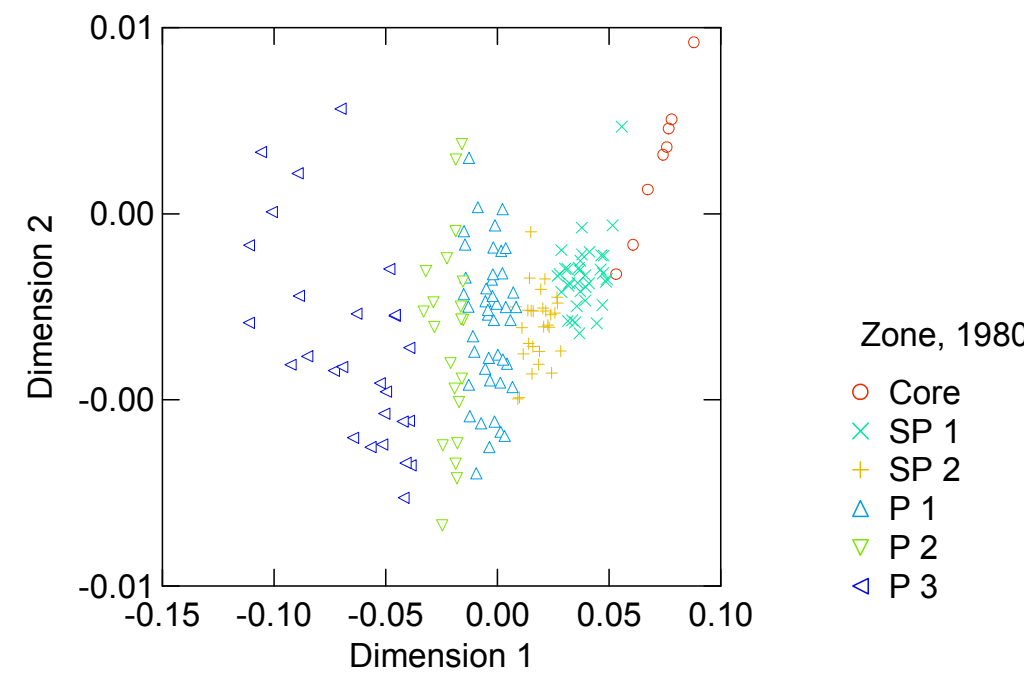

Figure 3: Correspondence Analysis of Regular Equivalence with Hierarchical Clustering Superimposed, 2001

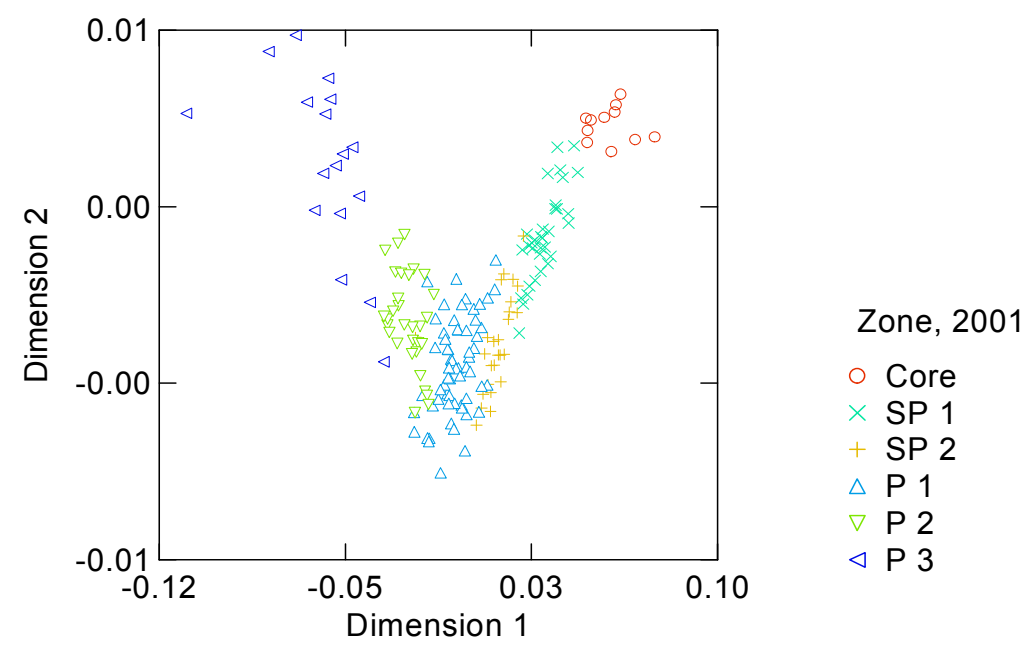

In both Figures, the countries on the positive (right hand) side of the origin are more "core like" than those on the negative side of the origin. The most extreme positive group appears 
to be the core. There are two groups between the core and the origin that we've labeled (2) Semiperiphery 1 and (3) Semi Periphery 2. Our fourth group-Periphery 1 -straddles the origin in each year, and the three lowest groups - (5) Periphery 2 and (6) Periphery 3 -correspond to an increasing negative distance from the origin. To summarize, we found six roughly equivalent positions in our data that we labeled Core, Semi-Peripheries 1 and 2, and Peripheries $1-3$. Semi-periphery 2 is less equivalent to the core than semi-periphery 1 ; periphery 2 is less equivalent to the core than periphery 1, etc., such that these positions capture the extent to which each position is successively less "core-like" as you move from right to left in Figures 2 and 3.

In order to verify that the first dimension is a continuous measure of "coreness," we can examine the reduced image matrix produced by collapsing the $\mathrm{N} \times \mathrm{N}$ trade matrices into a $6 \times 6$ matrix representing the six regularly equivalent positions. Recall that these positions simply represent "cut-points" along the continuous "coreness" dimension depicted in Figures 2 and 3. Thus, if the first dimension is a continuous measure of "coreness," one would expect to observe an interaction pattern reminiscent of the ideal typical one portrayed in Table 1 when examining the flows between groups. In other words, one would expect that this dimension captures the extent to which these data conform to a core / periphery structure.

Table 3: Values Represent Average Trade Within and Between Blocks in Thousands of US Dollars

\begin{tabular}{lrrrrrr}
\multicolumn{1}{c}{ 1980 } & Core & Semi-P 1 & Semi-P 2 & Periphery 1 & Periphery 2 & Periphery 3 \\
Core & $8,706,935$ & $1,409,369$ & 340,504 & 84,988 & 37,914 & 7,894 \\
Semi-P 1 & $1,663,029$ & 203,398 & 62,524 & 11,959 & 4,372 & 1,028 \\
Semi-P 2 & 298,919 & 32,734 & 12,669 & 3,384 & 1,783 & 783 \\
Periphery 1 & 80,192 & 6,394 & 2,292 & 1,133 & 366 & 151 \\
Periphery 2 & 21,013 & 2,231 & 628 & 123 & 123 & 75 \\
Periphery 3 & 2,791 & 212 & 107 & 26 & 53 & 1
\end{tabular}

Table 4: Values Represent Average Trade Within and Between Blocks in Thousands of US Dollars

\begin{tabular}{lrrrrrr}
\multicolumn{1}{c}{ 2001 } & Core & Semi-P 1 & Semi-P 2 & Periphery 1 & Periphery 2 & Periphery 3 \\
Core & $10,272,420$ & $1,367,748$ & 305,078 & 108,559 & 25,059 & 6,156 \\
Semi-P 1 & $1,553,314$ & 353,354 & 107,583 & 33,481 & 12,437 & 1,498 \\
Semi-P 2 & 383,887 & 88,335 & 21,573 & 8,545 & 5,087 & 132 \\
Periphery 1 & 79,924 & 17,413 & 3,246 & 2,970 & 1,044 & 193 \\
Periphery 2 & 9,969 & 3,211 & 649 & 447 & 421 & 208 \\
Periphery 3 & 1,671 & 320 & 39 & 59 & 121 & 12
\end{tabular}

The cells in tables 3 (1980) and 4 (2001) represent the average trade within and between each position in our analysis. The diagonal cells represent within position trade, while the off diagonal cells represent between position trade. The tables reveal a classic core / periphery interaction pattern: the largest cell represents the trade within the core, the peripheral groups are much more dependent upon the core than the other way around (comparing the core to periphery cells with the periphery to core cells), the periphery has only very minor interaction with itself, 


\section{JOURNAL OF WORLD-SYSTEMS RESEARCH}

and the semi-periphery has interaction patterns that are at once more "core like" than the periphery, but less "core like" than the core.

Table 5: Explained Variance of Regular Equivalence Matrix with First Five Dimensions of Correspondence Analysis

$\begin{array}{lcc}\text { Dimension 1 } & \mathbf{1 9 8 0} & \mathbf{2 0 0 1} \\ \text { Singular Value } & & \\ \text { PRE } & 0.041 & 0.031 \\ \text { Dimension 2 } & 97.18 & 97.30 \\ \text { Singular Value } & & \\ \text { PRE } & 0.004 & 0.004 \\ \text { Dimension 3 } & 0.89 & 1.36 \\ \text { Singular Value } & 0.004 & 0.002 \\ \text { PRE } & 0.86 & 0.54 \\ \text { Dimension 4 } & & \\ \text { Singular Value } & 0.003 & 0.002 \\ \text { PRE } & 0.40 & 0.35 \\ \text { Dimension 5 } & & \\ \text { Singular Value } & 0.002 & 0.001 \\ \text { PRE } & 0.29 & 0.13\end{array}$

As the above description suggests, the first-horizontal - dimension is consistent with a continuous measure of "coreness," where actors on the right are more "core like" than actors on the left. Thus, an obvious question to ask with this kind of information is how much of the variation in regular equivalencies can you explain with this simple one-dimensional core / periphery solution? Table 5 suggests that the variance explained by the first dimension - as shown in equation (4) above, is substantial, ranging from $97.18 \%$ of the variance in 1980 to $97.30 \%$ of the variance in 2001. In short, Figures 2 (1980) and 3 (2001), coupled with Tables 3 and 4 , reveal that the data do in fact correspond to a core / periphery structure, and Table 3 suggests that the fit of this model was fairly constant over the 21 year period under investigation.

In sum, our results suggest that the structure of global trade at both time points-1981 and 2001-exhibits the expected core / periphery interaction pattern, that there is a relatively distinct boundary between the core, periphery and semi-periphery, and that these conclusions are fairly stable across both time points studied. The results also suggest that, at least with respect to the data studied here, the core / periphery distinction is more continuous than discrete. This follows from the continuous break down of groups along the one dimensional correspondence analysis scaling, and the high amount of explained variance accounted for by the continuous first dimension of the correspondence analysis. More importantly, the results are consistent with those from previous trade research which found that cross-national relational data tends to exhibit a core / periphery interaction pattern. The implication is that this may be a fundamental feature to such data. The generality of this claim can be furthered if our finding can be replicated by an 
analysis that is distinct from the one performed above. We pursue this in our next section where we discuss the results of the exponential distance model, another structural approach to analyzing world trade data.

\section{EDM Results}

We begin our explanation of the results by returning to Figure 1 to differentiate this analysis from the Role and Position Analysis above. Step 1 in the first analysis involved taking the raw trade data and analyzing it with an equivalence criterion, e.g., regular equivalence (RE) in this case. Steps 2 and 3, the categorical and continuous scaling of the equivalence matrix, are carried out on the RE matrix as opposed to the raw trade matrix. Therefore, the underlying data applied to the $\mathrm{CA}$ above is an equivalence rather than a raw trade value. In other words, cells $i j$ in an equivalence matrix quantifies how similar actor $i$ 's overall trade pattern are to actor $j$ 's overall trade pattern. In the EDM analysis, we skipped step 1 and submitted the raw trade data to the EDM. Thus the data analyzed by the EDM is frequency rather than similarity data. In other words, cell $i j$ in the raw trade matrix quantifies the volume of trade between actors $i j$ rather than the similarity in overall trade patterns between $i$ and $j$..

\section{Figure 4: Exponential Distance Model with Hierarchical Clustering of Regular Equivalencies Superimposed, 1980}

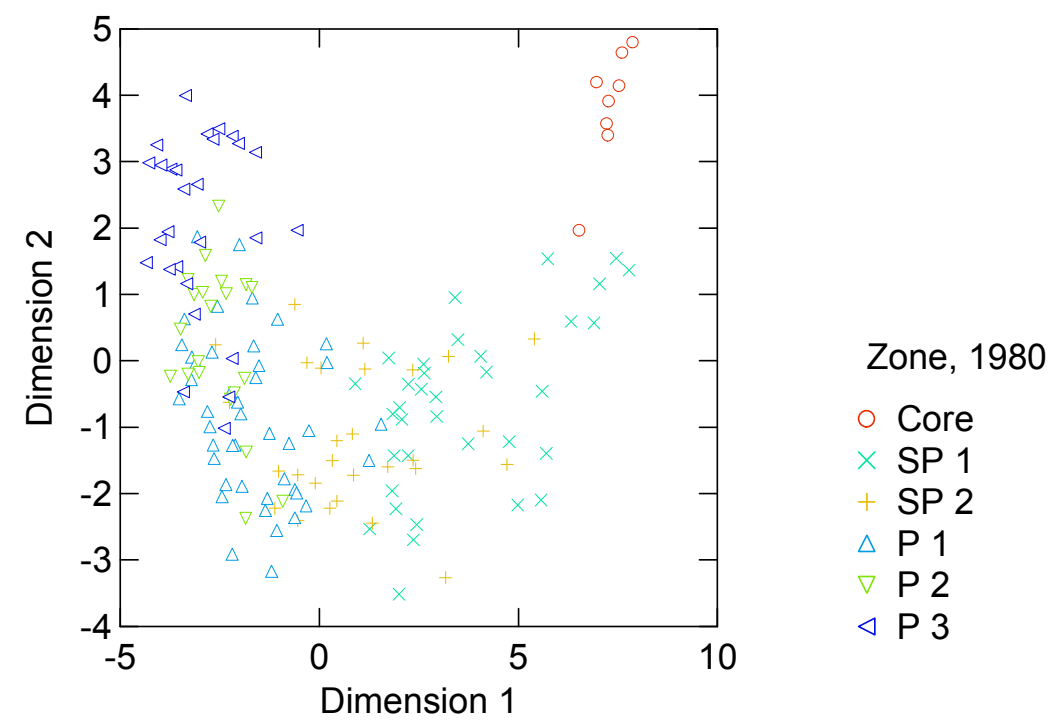

Figures 4 and 5 represent the first and second dimensions from the EDM analysis with the groups from the previous analysis superimposed. Similar to Figures 2 and 3, the distance between the points in the EDM graphs represent dissimilarity in patterns of trade. Figure 4 shows the results for the EDM for 1980. There is a clear cluster of core countries in the upper right hand 


\section{JOURNAL OF WORLD-SYSTEMS RESEARCH}

corner of the figure. ${ }^{13}$ Countries that were identified as members of semi-peripheries 1 and 2 in the Role and Positional Analysis are located in closest proximity to the core, followed by countries which were identified as part of the periphery (P1-P3 in the prior analysis). Figure 5, the graph for 2001, is very similar to that of the 1980 graph, suggesting very little change in global trade patterns in the post-Cold War era despite predictions to the contrary. What has changed of course is the composition of the groups as many countries (most notably China) have experienced mobility.

Figure 5: Exponential Distance Model with Hierarchical Clustering of Regular Equivalencies Superimposed, 2001

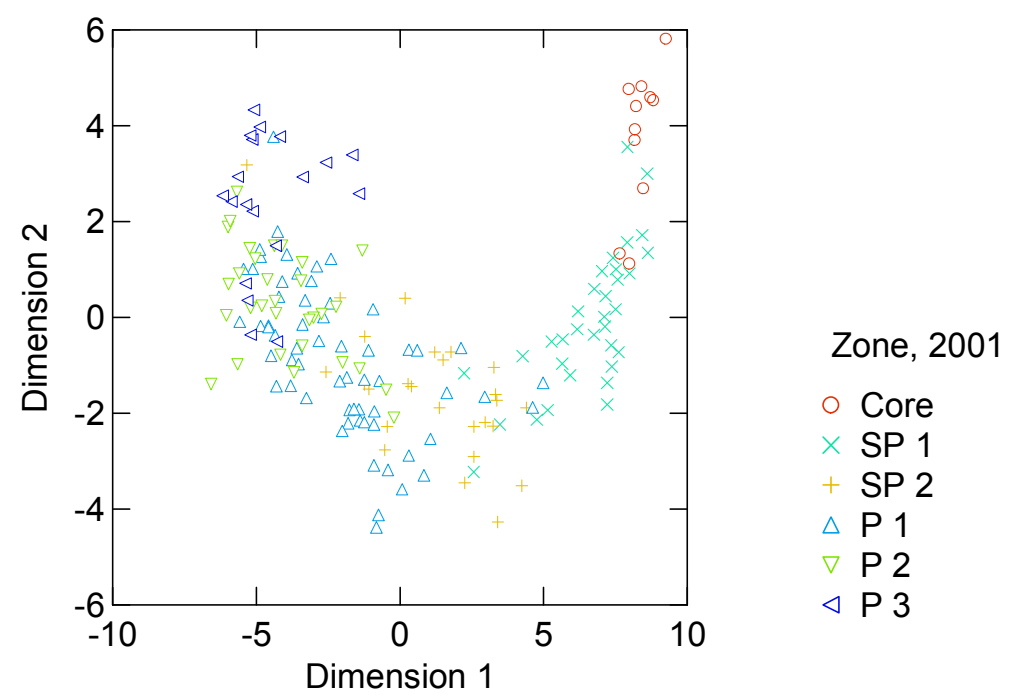

\section{Comparing the Two Models}

The correspondence between the results of these two very different analyses is striking. First, Figures 2 and 3 depicted a single coreness vector along the horizontal axis, and the superimposed groups gave a sense of the extent to which countries could be placed into relatively equivalent groups along the continuous core / periphery dimension. By looking at the correspondence between the groups from the first analysis and the first dimension from the EDM analysis, it becomes clear that the first dimension from the latter analysis is also capturing a continuous measure of "coreness." The "core" groups are located in the upper right quadrant in both sets of graphs, and the groupings are increasingly "peripheral" as you move from right to left. In order to quantify the similarity, we correlated these two dimensions and report these values in Table 6. There was a correlation of .739 in 1980 and .872 in 2001, indicating high similarity in the underlying structure identified by these two methods.

${ }^{13}$ See Table A1a through A2b in the Appendix for the full country names and EDM coordinates. 
LOOKING BACK AND FORGING AHEAD 72

Table 6: Correlation Coefficients Between First Dimensions of the Exponential Distance Model and Correspondence Analysis of Regular Equivalencies

\begin{tabular}{ccc} 
& \multicolumn{2}{c}{ CA of RE } \\
& Year & $\boldsymbol{r}$ \\
EDM & 1980 & 0.739 \\
& 2001 & 0.872
\end{tabular}

\section{CONCLUSION}

This paper reviewed two lineages of empirical research on the world-system that utilize social network methods. Despite the fact that each lineage approaches their analyses with very different sources of data - either both economic and non-economic data or multiple commodity trade relations - our review highlighted much similarity across the two approaches in terms of the kinds of questions that are asked of the data, as well as the findings. In particular, they share a common approach to the identification of Roles and Positions from SNA and an evolution toward less restrictive equivalence criterion over time. Further, there is overwhelming support for the notion that cross-national trade data exhibit a core / periphery interaction pattern.

Our analyses of the trade data drew attention to various analytical decisions that need to be made including how to conduct a simultaneous analysis of multiple relations, the best way to choose between and implement different equivalence criterion, how to select and interpret clustering algorithms, and a practical approach to generating a consistent set of equivalence groupings. These analyses should provide a reasonable road map to future researchers interested in applying these methods or developing new ones, either in the tradition of the classic approach to network roles and positions or the tradition of reduced rank techniques that work well on raw frequency data such as the EDM model (e.g. Borgatti and Everett 1999; Boyd et al. 2006a; 2006b; De Leeuw and Mair, 2008; Handcock, Raftery and Tantrum 2007; Weller and Romney 1990).

Our results generally support the lineage of research dating back to 1979 across two different methodological approaches. Our findings suggest that the main dimension of crossnational variation in trade can be interpreted as a continuous core / periphery dimension, and the association between relative positions of countries along this core / periphery dimension across the two methods is high and growing over time. The implication is that a core / periphery interaction pattern appears to be a fundamental feature of cross-national trade data. Yet neither we, nor the papers we reviewed above, establish a "null hypothesis" to test whether or not a network conforms to a core / periphery structure. In other words, many networks may exhibit varying degrees of a core / periphery structure. It is not clear whether or not cross-national networks like those analyzed here are more like ideal core / periphery structures than one might observe on any randomly selected group of networks with similar characteristics (such as size, density, degree distribution, etc.).

While it is beyond the scope of this article to address the various statistical particularities of network data, it should suffice to say that relational data do not meet standard statistical 


\section{JOURNAL OF WORLD-SYSTEMS RESEARCH}

assumptions such as random sampling and independent units. Early statistical analyses focused on non-parametric approaches such as the quadratic assignment procedure (QAP). For example, a QAP could be used to "test" the fit of a core / periphery model as follows. Step one would involve computing a correlation coefficient between a derived block model such as illustrated in Tables 4 and 5, and an ideal-typical model similar to the one illustrated in Table 1. The next step would involve multiple iterations of random permutations of the derived block model. The last step would involve computing a new correlation coefficient at each permutation in order to determine the frequency of random correlations as large as the one observed, using standard thresholds as benchmarks. An alternative strategy for continuous core / periphery structures would simply be to correlate the matrix that results from the product of the derived "coreness" vector and its transpose (e.g., the product $\mathrm{cc}^{\mathrm{T}}$ where $\mathrm{c}$ is a derived measure of "coreness") with the observed matrix, and then continue through steps 2 and 3 by permuting the $\mathrm{cc}^{\mathrm{T}}$ product matrix an appropriate number of times. ${ }^{14}$ Other non-parametric approaches, such as the jackknife and bootstrap, may be equally useful as a first approximation in either the categorical or continuous cases (e.g. Snijders and Borgatti 1999).

Another potential methodological advance for this literature may involve using the structural approach to predict the presence, absence or volume of some type of relationship between two actors as a function of their position in the global economic network. Early approaches such as QAP regression may work as a first approximation, but they rest on the somewhat dubious assumption of dyadic independence (see Alderson and Beckfield 2004 for a recent application). Recent advances in statistical network models including the exponential random graph (ERG) model (Anderson, Wasserman and Crouch 1999; Contractor, Wasserman and Faust 2006; Holland and Leinhardt 1975; 1981, Robins and Morris 2007) or the stochastic block model (see Wasserman and Faust 1994: 675-723 for a general introduction; Nowicki and Snijders 2001; Snijders and Nowicki 1997; Wang and Wong 1987) may take us in the right direction.

ERG models relax the assumption of dyadic independence, and provide a useful (but complicated) way to conceptualize a set of ties between actors as random variables that arise as a function of the interdependencies among the set of ties. The ERG family of models are fairly young in their development, however, and deciding upon a set of parameters can seem somewhat arbitrary (e.g. Goodreau 2007). Further, the models proposed in the literature generally focus on modeling individual level data such as friendship, such that their extension to cross-national data may not be obvious. Stochastic block models, on the other hand, may be useful in several ways. First, they may provide the means to engage in hypothesis testing with respect to the correct assignment of actors to subgroups (steps 2 and 3 in Figure 1 above), and whether or not the pattern of relations within and between subgroups bears a higher degree of association to an ideal-typical block model than one would expect by chance. ${ }^{15}$ Second, they may provide the means to determine how well a core / periphery model explains a set of cross-national relational

${ }^{14}$ Recent work suggests that replacing the product $\mathrm{cc}^{\mathrm{T}}$ with the product of the first UV from an SVD with imputed diagonal elements may make more sense in the presence of strong asymmetry (Boyd et al. 2006b).

${ }_{15}$ Also see Handcock, Raftery, and Tantrum 2007 for a very recent model based clustering approach. 
data compared to some other theoretically derived ideal-typical model. Both approaches suggest that future research should consider incorporating model based statistical network methods.

Another useful line of inquiry could be using the results of structural analyses as both dependent and independent variables in regression analyses. For example, scholars disagree on how the structure of the world economy is impacted by globalization processes. Future studies can further explore both the determinants of a country's position in the structure of the worldsystem, and the consequences of occupying a given position. The EDM model and other similar approaches may be useful for modeling the determinants of world-system position.

As we have seen, the EDM model for independent Poisson frequencies in a square table has expected values of the form

$$
\lambda_{i j}=\exp \left\{\alpha_{\mathrm{i}}+\beta_{\mathrm{j}}-\left|x_{\mathrm{i}}-x_{\mathrm{j}}\right|\right\}
$$

where the $\left|x_{i}-x_{j}\right|$ are Euclidean distances between points in "latent space". The software for the EDM method can also handle versions of the model where distances are replaced by either squared distances or inner products.

EDM is very similar to the model implemented in the latentnet package for social network analysis (Hoff et al. 2002, Shortreed et al. 2006, Krivitsly and Handcock 2008), although the algorithms used are completely different. The latentnet model in the Poisson case is

$$
\left(\lambda_{i j}=\exp \left\{\sum_{\mathrm{p}=1}^{\mathrm{s}} y_{i j p} \beta_{p}-\left|x_{\mathrm{i}}-x_{\mathrm{j}}\right|\right\}\right.
$$

Thus latentnet is similar to EDM, because it allows for a geometrical representation of interaction in latent space, using the points $x_{i}$. In addition it incorporates regression on one or more external variables. In future versions of the EDM method we intend to implement similar linear restrictions, in addition to various linear restrictions on the coordinates in latent space. In short, either the procedure implemented in latentent or our own future version will be amenable to including both attributes and relational data on the right hand side of an equation designed to understand what factors determine the placement of countries in the structure of the worldsystem.

Some of the classic questions addressed thus far in terms of the consequences for occupying a given structural position include economic growth (e.g. Snyder and Kick 1979; Nemeth and Smith 1985), within country inequality (Alderson and Nielsen 1999; Nemeth and Smith 1985), between-country inequality (Peacock, Hoover and Killian 1988) and other indicators of development. While some of the attribute-based quantitative efforts to pursue hypotheses related to world-systems analysis - such as the foreign capital penetration literatures (Firebaugh 1992; c.f. Dixon and Boswell 1996) or studies of global income inequality (Korzeniewicz and Moran 2000, 1997; c.f. Firebaugh 1999, 2003)—were met with critique on either empirical or substantive grounds, the relational approach of social network analysis has fared much better (c.f. Chase-Dunn and Grimes 1995: 398; Van Rossem 1997). Thus, new studies on the question of the developmental consequences for structural position may provide a means by which to revitalize the position of world-systems analysis in the social sciences. 


\section{JOURNAL OF WORLD-SYSTEMS RESEARCH}

Given that the world-system perspective gives causal priority to the position of countries in the structure of the world-system, one particularly important question could be that of mobility. Surprisingly, a small amount of research has been done on the question of upward / downward mobility in the world-system (Bornschier and Trezzini 1997) from either a network analytic approach (c.f. Mahutga 2006; Smith and White 1992) or other approaches (c.f. Arrighi and Drangle 1986; Babones 2005; Terlouw 1993). While much of the explanation for this empirical gap may be found in the presumed stability of the world-system, we suggest that studying the question of mobility is an important direction for future research, and is already underway in some cases (e.g., Clark 2008). Indeed, understanding both the determinants of and consequences for mobility in the world-system could contribute to classic questions of interest to world-system theorists, including a mainstream explanation for development and underdevelopment in the world-economy and the rise and fall of hegemonic powers.

Finally, the increasing interdependence of nation-states beyond economic relations suggests additional avenues for research to examine hypotheses derived from world systems analysis. New substantive foci include world-polity embeddedness (Beckfield 2003) and human rights and geo-political alignments (Lloyd 2007).

\section{REFERENCES}

Alderson, Arthur and Jason Beckfield. 2004. "Power and Position in the World City System." American Journal of Sociology 109(4):811-51.

Alderson, Arthur and Francois Nielsen. 1999. "Income Inequality, Development and Dependence: A Reconsideration.” American Sociological Review 64: 606-31.

Anderson, Carolyn, Stanley Wasserman and Bradley Crouch. 1999. "A $p$ * Primer: Logit Models for Social Networks." Social Networks 21(1):37-66.

Anheier, Helmut K and Jurgen Gerhards. 1991. "Literary Myths and Social Structure." Social Forces 69(3):811-830.

Arrighi, Giovani. 1994. The Long Twentieth Century. London: Verso.

Arrighi, Giovanni and Jessica Drangel. 1986. "The Stratification of the World-Economy: An Exploration of the Semiperipheral Zone." Review 10(1):9-74.

Babones, Salvatore. 2005. "The Country-Level Income Structure of the World-Economy." Journal of World-Systems Research 11(1): 29-55.

Beckfield, Jason. 2003. Inequality in the World Polity: The Structure of International Organization." American Sociological Review 68:401-24.

Bishop, Yvonne, Stephen Fienberg, and Paul Holland. 1975. Discrete Multivariate Analysis: Theory and Practice. MA: MIT Press.

Blanton, Robert G. 1999a. "Structure and Behavior in the World Trading System." International Interactions 25(2): 119-44.

. 1999b. "Trading Blocs and the Capitalist World-Economy: Insights and Evidence." Sociological Inquiry 69(2):187-215.

Bollen, Kenneth. 1983. "World System Position, Dependency and Democracy: The CrossNational Evidence." American Sociological Review 84:468-79.

Bollen, Kenneth and Stephen Appold. 1993. "National Industrial Structure and the Global System.” American Sociological Review 50:438-57. 
Bornschier, Volker and Bruno Trezzini. 1997. "Social Stratification and Mobility in the World System: Different Approaches and Recent Research.” International Sociology 12(4):42955.

Boorman, Scott A. and Harrison White. 1976. "Social Structure from Multiple Networks. II Roles Structures." American Journal of Sociology 81(6): 1384-1446

Borgatti, Stephen. 1994. "How to Explain Hierarchical Clustering." Connections 17(2):81-4.

Borgatti, Stephen and Martin Everett. 1999. "Models of Core / Periphery Structures." Social Networks 21:375-95.

. 1992. "Regular Block Models of Multiway, Multimode Matrices." Social Networks 14:91120.

Borgatti, Stephen, Martin Everett and Linton Freeman. 2002. UCINET. Harvard Analytical Technologies.

Bourgeois, Michael, and Noah E. Friedkin. 2001. "The Distant Core: Social Solidarity, Social Distance and Interpersonal Ties in Core-periphery Structures." Social Networks 24(4):245-260.

Boyd, John P., William J. Fitzgerald, and Robert J. Beck. 2006a. "Computing Core/Periphery Structures and Permutation Tests for Social Relations Data." Social Networks 28(2):165-178.

Boyd, John, William Fitzgerald, Matthew C. Mahutga and David A. Smith. 2006b. "Computing Continuous Core/Periphery Structures for Social Relations Data Using MINRES SVD." Paper presented at the $26^{\text {th }}$ annual Sunbelt Social Network Conference. Friday, April 28. Vancouver, British Columbia, Canada.

Breiger, Ronald. 1981. "Structures of Economic Interdependence Among Nations." Pp. 353-79 in Continuities in Structural Inquiry, edited by Peter M Blaue and Robert K Merton, London: Sage Press.

Breiger, Ronald L., Scott A. Moorman, and Phipps Arabie. 1975. "An Algorithm for Clustering Relational Data with Applications to Social Network Analysis and Comparison with Multidimensional Scaling." Journal of Mathematical Psychology 12:328-83.

Burris, Val. 2004. "The Academic Caste System: Prestige Hierarchies in PhD Exchange Networks." American Sociological Review 69(2):239-264.

Christley, R. M., G. L. Pinchbeck, R. G. Bowers, D. Clancy, N. P. French, R. Bennett, and J. Turner. 2005. "Infection in Social Networks: Using Network Analysis to Identify HighRisk Individuals." American Journal of Epidemiology 162(10):1024-1031.

Chase-Dunn, Christopher. 1998. Global Formation. Oxford: Rowman \& Littlefield.

Chase-Dunn, Christopher and Peter Grimes. 1995. "World-Systems Analysis." Annual Review of Sociology 21: 387-417.

Chase-Dunn, Christopher and Richard Rubinson. 1977. "Toward a Structural Perspective on the World-System." Politics and Society 7(4):453-76.

Clark, Robert. 2008. "Dependency, Network Integration, and Development." Sociological Perspectives. 51(3):629-648.

Contractor, Noshir, Stanley Wasserman and Katherine Faust. 2006. "Testing multi-theoretical multilevel hypotheses about organizational networks: An analytic framework and empirical example." Academy of Management Journal 31(3):681-703.

Cummings, Jonathan N., and Robert Cross, 2003. "Structural Properties of Work Groups and their Consequences for Performance." Social Networks 25(3):197-210. 
De Leeuw, Jan. 1994. "Block Relaxation Algorithms in Statistics," in Information Systems and Data Analysis, edited by H.H. Bock, Berlin: Springer.

De Leeuw, Jan. and Patrick Mair. 2007. "Homogeneity Analysis in R: The Package Homals." Journal of Statistical Software paper 2007010117.

De Nooy, Wouter, Andrej Mrvar and Vladimir Batagelj. 2005. Exploratory Social Network Analysis with Pajek. Cambridge: Cambridge University Press.

Dicken, Peter. 2003. Global Shift. New York: Guilford Press.

Dixon, William and Terry Boswell. 1996. "Dependency, Disarticulation, and Denominator Effects: Another Look at Foreign Capital Penetration." American Journal of Sociology 102:543-562.

Dodsworth, Robin. 2005. "Attribute Networking: A Technique for Modeling Social Perceptions." Journal of Sociolinguistics 9(2):225-253.

Doreian, Patrick, Vladimir Batagelj and Anuska Ferligoj. 2005. "Positional Analysis of Sociometric Data." Pp. 77-97 in Models and Methods in Social Network Analysis, edited by Peter J. Carrington, John Scott and Stanley Wasserman, Cambridge: Cambridge University Press.

Duff, Andrew. I. 1996. "Ceramic Micro-Seriation: Types or Attributes." American Antiquity 61: 89-101.

Emmanuel, Arghiri. 1972. Unequal Exchange: A Study of the Imperialism of Trade. New York: Monthly Review Press.

Faust, Katherine. 1988. "Comparison of Methods for Positional Analysis: Structural and General Equivalences." Social Networks 10:313-41.

Feenstra, Robert C., James R. Markusen, and Andrew K. Rose. 2001. "Using the Gravity Equation to Differentiate among Alternative Theories of Trade." The Canadian Journal of Economics 34(2):431-447.

Firebaugh, Glenn. 2003. The New Geography of Global Income Inequality. Cambridge: Harvard University Press.

1999. "Empirics of World Income Inequality." American Journal of Sociology 104(6):1597-1630.

1992. "Growth Effects of Foreign and Domestic Investment." American Journal of Sociology 98:105-30

Frank, Andre Gunder. 1969. Latin American: Underdevelopment or Revolution. New York: Monthly Review.

Galtung, Johan. 1971. "A Structural Theory of Imperialism." Journal of Peace Research 2:81117.

Giuliani, Elisa, and Martin Bell. 2005. "The Micro-determinants of Meso-level Learning and Innovation: Evidence from a Chilean Wine Cluster." Research Policy 34(1):47-68.

Goodman, Leo A. 1991. "Measures. Models, and Graphical Displays in the Analysis of Crossclassified Data (with discussion)." Journal of the American Statistical Association 86: 1085-1137.

Goodreau, Steven M. 2007. "Advances in Exponential Random Graph ( $\left.p^{*}\right)$ Models Applied to a Large Social Network." Social Networks 29(2):231-48.

Haberman, Shelby. J. 1974. The Analysis of Frequency Data. Chicago: University of Chicago Press. 
Handcock, Mark S., Adrian Raftery, Jeremy M. Tantrum. 2007. "Model Based Clustering for Social Networks." Journal of the Royal Statistical Society 170(2):1-22

Hirschman, Albert O. [1945] 1980. National Power and the Structure of Foreign Trade. Berkeley: UC Press.

Hoff, Peter. D., Adrian.E. Raftery, and Mark. S. Handcock. 2002. "Latent Space Approaches to Social Network Analysis" Journal of the American Statistical Association 97: 1090-1098

Holland, Paul W., and Samuel Leinhardt. 1981. "An Exponential Family of Probability Distributions for Directed Graphs (With Discussion)." Journal of the American Statistical Association 76:33-65.

. 1975. "Local Structure in Social Networks." Sociological Methodology 19:1-45.

Hopkins, Terence K. 1978. "World-System Analysis: Methodological Issues." Pp. 199-218 in Social Change in the Capitalist World Economy, edited by Barbara Hockey Kaplan, Beverly Hills: Sage.

Hopkins, Terrance and Immanuel Wallerstein. 1986. "Commodity Chains in the World Economy Prior to 1800." Review 10(1):157-70.

. 1977. "Patterns of Development of the Modern World-System." Review 1(2): 11-145.

Johnson, Jeffrey C., James S. Boster, and Lawrence A. Palinkas. 2003. "Social Roles and the Evolution of Networks in Extreme and Isolated Environments." Journal of Mathematical Sociology 27:89-121.

Jolly, A. M., S. Q. Muth, J. L. Wylie, and J. J. Potterat, 2001. "Sexual Networks and Sexually Transmitted Infections: A Tale of Two Cities." Journal of Urban Health - Bulletin of the New York Academy of Medicine 78(3):433-445.

Kick, Edward L. and Byron L. Davis. 2001. "World-System Structure and Change: An Analysis of Global Networks and Economic Growth Across Two Time-Periods." American Behavioral Scientist 44(10):1567-78.

Kim, Sangmoon and Eui-Hang Shin. 2002. "A Longitudinal Analysis of Globalization and Regionalization in International Trade: A Social Network Approach." Social Forces 81(2):445-71.

Korzeniewicz, Roberto Patricio and Timothy Patrick Moran. 2000. "Measuring World Income Inequalities." American Journal of Sociology 106(1):209-21.

. 1997. "World-Economic Trends in the Distribution of Income, 1965-1992." American Journal of Sociology 102(4):1000-1039.

Krackhardt, David. 1999. "The Ties That Torture: Simmelian Tie Analysis in Organizations." Research in the Sociology of Organizations 16:183-210.

Krivitsky, Pavel N. and Mark S. Handcock 2008. "Fitting Latent Cluster Models for Social Networks with latentnet." Journal of Statistical Software 24(5):1-23.

LeBlanc, Steven A. 1975. "Micro-Seriation: A Method for Fine Chronologic Differentiation." American Antiquity 40:22-38

Lloyd, Paulette 2007. "Mapping the World Order: A Reassessment of Huntington's Clash of Civilizations. Conference Paper, International Sunbelt Social Network Conference, Corfu, Greece, May 4, 2007 and Conference for Advanced Political Network Modeling, University of Mannheim, Germany, June 26-28, 2007.

London, Bruce. 1987. "Structural Determinants of Third World Urban Change: An Ecological and Political Analysis." American Sociological Review 52:28-43. 
Mahutga, Matthew C. 2006. "The Persistence of Structural Inequality? A Network Analysis of International Trade, 1965-2000.” Social Forces 84(4): 1863-89.

Mullins, Nicholas C., Lowell L Hargens, Pamela K. Hecht, Edward L Kick. 1977. "The Group Structure of Cocitation Clusters: A Comparative Study." American Sociological Review 42(4):552-562.

Nowicki, Krzysztof and Tom A. B. Snijders. 2001. "Estimation and Prediction for Stochastic Blockstructures." Journal of the American Statistical Association 96(455):1077-1087.

Nemeth, Roger J. and David A. Smith. 1985. "International Trade and World System Structure: A Multiple Network Analysis." Review 8(4):517-160.

O'Hearn, Dennis. 2001. The Atlantic Economy: Britain, The U.S. and Ireland. Manchester: Manchester University Press.

Peacock, Walter, Greg Hoover and Charles Killian. 1988. "Divergence and Convergence in International Development: A Decomposition of Inequality in the World-System." American Sociological Review 53:838-52.

Prebisch, Raul 1950. The Economic Development of Latin America and Its Principal Problems. New York: United Nations.

Robins, Gary and Martina Morris (eds). 2007. "Special Section: Advances in Exponential Random Graph (p*) Models." Social Networks 29(2):169-348

Romney, A. Kimball, Carmella C. Moore, and Timothy J. Brazill. 1998. Correspondence analysis as a multidimensional scaling technique for non-frequency similarity matrices. Pages 329-345 in Visualization of Categorical Data, edited by Joerg Blasius and Michael Greenacre, San Diego: Academic Press.

Shortreed, Susan., Mark Handcock, and Peter Hoff. 2006. "Positional Estimation within the Latent Space Model for Networks." Methodology 2(1):24-33.

Singer, Hans W. 1950. "The Distribution of Gains Between Investing and Borrowing Countries." American Economic Review 40(2):473-85.

Smith, David A and Roger J. Nemeth. 1988. "Research Note: An Empirical Analysis of Commodity Exchange in the International Economy: 1965-1980." International Studies Quarterly 32:227-240.

Smith, David A and Douglas R. White. 1992. "Structure and Dynamics of the Global Economy: Network Analysis of International Trade 1965-1980. Social Forces 70(4):857-893.

Smith, David A. and Michael Timberlake. 2001. "World city networks and hierarchies, 19771997: an empirical analysis of global air travel links." American Behavioral Scientist. 44: $1656-1678$

Snijders, Tom and Stephen Borgatti. 1999. "Non-Parametric Standard Errors and Tests for Network Statistics." Connections 22(2):161-70.

Snijders, Tom A. B. and Krzysztof. Nowicki. 1997. "Estimation and prediction for stochastic blockmodels for graphs with latent block structure." Journal of Classification 14(1):75.

Snyder, David and Edward L. Kick. 1979. "Structural Position in the World System and Economic Growth, 1955-1970: A Multiple-Network Analysis of Transnational Interactions." American Journal of Sociology 84(5):1096-1126.

Statistics Canada. 2008. World Trade Analyzer. Ottawa, Canada. $<$ http://www.statcan.ca/english/Dli/Data/Ftp/worldtrade.htm $>$

Su, Tie Ting and Dan Clawson. 1994. "Trade Networks, Trade Blocks, and Hegemonic Conflict." Sociological Inquiry 64(4):415-37. 
Taylor, Peter J. 2004. World City Network: A Global Urban Analysis. London: Routledge.

Terlouw, Charles P. 1993. "The Elusive Semiperiphery: A Critical Examination of the Concept of Semiperiphery." International Journal of Comparative Sociology 34(1-2):87-102.

Uzzi, Brian, and Jarrett Spiro. 2005. "Collaboration and Creativity: The Small World Problem." American Journal of Sociology 111(2):447-504.

Van Rossem, Ronan. 1996. "The World-System Paradigm as General Theory of Development: A Cross-National Test." American Sociological Review 61(3):508-27.

Wallerstein, Immanuel. 1989 The Modern World-System III. Berkeley: Academic Press.

. 1974. The Modern World-System I: Capitalist Agriculture and the Origins of the European World-Economy in the Sixteenth Century. Berkeley: Academic Press.

Wang, Yuchung J and George Y Wong. 1987. "Stochastic Blockmodels for Directed Graphs." Journal of the American Statistical Association 82(397):8-19.

Wasserman, Stanley and Katherine Faust. 1994. Social Network Analysis: Methods and Applications. Cambridge: Cambridge University Press.

Wejnert, Barbara. 2005. "Diffusion, Development and Democracy, 1800-1999." American Sociological Review 70:53-81.

Weller, Susan and Kimball A. Romney. 1990. Metric Scaling: Correspondence Analysis. A Sage Paper Series: Quantitative Applications in the Social Sciences. London: Sage.

White, Douglas and Karl P. Reitz. 1985. "Measuring Role Distance: Structural, Regular and Relational Equivalence." Unpublished Manuscript. UC Irvine.

White, Harrison, Scott Boorman and Ronald Breiger. 1976. "Social Structure From Multiple Networks. I. Blockmodels of Roles and Positions." American Journal of Sociology 81: 730-80. 


\section{JOURNAL OF WORLD-SYSTEMS RESEARCH}

\section{Appendix A: Countries Included in the Analysis, Position and Coordinates for the CA of RE and EDM models ${ }^{16}$}

Table A1a: Core and Semi-Periphery in 1980, ranked by position and CA of RE

\begin{tabular}{|c|c|c|c|c|c|c|c|}
\hline Country & Position & CA of RE & EDM & Country & Position & CA of RE & EDM \\
\hline & & 1st Dim & 1st Dim & & & 1st Dim & 1st Dim \\
\hline United States & 1 & 0.088 & 6.966 & Argentina & 2 & 0.031 & 2.003 \\
\hline Germany & 1 & 0.078 & 7.873 & South Africa & 2 & 0.031 & 1.885 \\
\hline Japan & 1 & 0.077 & 7.268 & Malaysia & 2 & 0.030 & 2.361 \\
\hline United Kingdom & 1 & 0.076 & 7.223 & Indonesia & 2 & 0.029 & 1.833 \\
\hline France & 1 & 0.074 & 7.532 & Hungary & 2 & 0.029 & 2.074 \\
\hline Italy & 1 & 0.067 & 7.612 & Algeria & 2 & 0.028 & 2.018 \\
\hline Netherlands & 1 & 0.061 & 7.251 & Mexico & 2 & 0.027 & 2.450 \\
\hline Belgium-Luxembourg & 1 & 0.053 & 6.532 & Romania & 3 & 0.028 & 1.110 \\
\hline Saudi Arabia & 2 & 0.056 & 5.601 & Greece & 3 & 0.027 & 5.402 \\
\hline Former USSR & 2 & 0.052 & 3.485 & Thailand & 3 & 0.027 & 2.426 \\
\hline Brazil & 2 & 0.049 & 2.620 & Former E Germany & 3 & 0.026 & 1.152 \\
\hline Singapore & 2 & 0.048 & 3.740 & Turkey & 3 & 0.024 & 0.446 \\
\hline Iraq & 2 & 0.048 & 1.846 & Israel & 3 & 0.024 & 1.727 \\
\hline Canada & 2 & 0.047 & 7.042 & Chile & 3 & 0.023 & -0.098 \\
\hline Spain & 2 & 0.047 & 5.737 & Netherlands Antilles & 3 & 0.023 & -2.258 \\
\hline Sweden & 2 & 0.047 & 7.779 & New Zealand & 3 & 0.022 & 3.171 \\
\hline Switzerland & 2 & 0.046 & 7.458 & Philippines & 3 & 0.021 & 1.335 \\
\hline China & 2 & 0.044 & 2.636 & Portugal & 3 & 0.021 & 4.119 \\
\hline Australia & 2 & 0.041 & 4.984 & Ireland & 3 & 0.020 & 4.718 \\
\hline Poland & 2 & 0.041 & 2.563 & Colombia & 3 & 0.019 & 0.859 \\
\hline Iran & 2 & 0.039 & 2.238 & Egypt & 3 & 0.019 & 2.358 \\
\hline Taiwan & 2 & 0.039 & 4.200 & Pakistan & 3 & 0.018 & 3.244 \\
\hline Hong Kong & 2 & 0.039 & 5.703 & Peru & 3 & 0.016 & 0.265 \\
\hline Venezuela & 2 & 0.038 & 1.267 & Qatar & 3 & 0.016 & -1.018 \\
\hline Nigeria & 2 & 0.038 & 2.952 & Bulgaria & 3 & 0.015 & 0.050 \\
\hline Libya & 2 & 0.037 & 0.904 & Cote d'Ivoire & 3 & 0.015 & -0.306 \\
\hline United Arab Emirates & 2 & 0.037 & 2.232 & Bahamas & 3 & 0.015 & -2.604 \\
\hline Austria & 2 & 0.037 & 6.323 & Trinidad \&Tobago & 3 & 0.014 & -1.110 \\
\hline Fmr. Czechoslovakia & 2 & 0.037 & 1.747 & Bahrain & 3 & 0.014 & -0.534 \\
\hline South Korea & 2 & 0.036 & 2.928 & Morocco & 3 & 0.014 & 2.354 \\
\hline Kuwait & 2 & 0.036 & 1.921 & Syria & 3 & 0.012 & 0.835 \\
\hline Denmark & 2 & 0.035 & 6.899 & Ecuador & 3 & 0.011 & -0.537 \\
\hline
\end{tabular}

${ }^{16} \mathrm{~N}=164$ for $1980 ; \mathrm{N}=181$ for 2001 
Table A1a continued

\begin{tabular}{|c|c|c|c|c|c|c|c|}
\hline Former Yugoslavia & 2 & 0.035 & 3.412 & Cuba & 3 & 0.010 & -0.616 \\
\hline India & 2 & 0.033 & 4.054 & Kenya & 3 & 0.009 & 0.447 \\
\hline Finland & 2 & 0.032 & 4.769 & Tunisia & 3 & 0.008 & 0.333 \\
\hline Norway & 2 & 0.032 & 5.571 & & & & \\
\hline
\end{tabular}

Table A1b: Periphery in 1980, ranked by position and CA of RE

\begin{tabular}{|c|c|c|c|c|c|c|c|}
\hline Country & Position & CA of RE & EDM & Country & Position & CA of RE & EDM \\
\hline & & 1st Dim & 1st Dim & & & 1st Dim & 1st Dim \\
\hline Guatemala & 4 & 0.008 & -2.050 & Malawi & 5 & -0.016 & -2.454 \\
\hline Oman & 4 & 0.007 & -0.879 & Fiji & 5 & -0.016 & -3.293 \\
\hline Angola & 4 & 0.007 & -1.043 & Mali & 5 & -0.016 & -2.722 \\
\hline Lebanon & 4 & 0.006 & 1.555 & Uganda & 5 & -0.017 & -3.481 \\
\hline Uruguay & 4 & 0.004 & -1.349 & Albania & 5 & -0.018 & -2.522 \\
\hline Costa Rica & 4 & 0.004 & -1.938 & Vietnam & 5 & -0.018 & -1.690 \\
\hline Zaire & 4 & 0.004 & -1.595 & Reunion & 5 & -0.019 & -2.136 \\
\hline Sri Lanka & 4 & 0.003 & 0.179 & Barbados & 5 & -0.019 & -2.226 \\
\hline Zambia & 4 & 0.002 & -1.647 & Zimbabwe & 5 & -0.019 & -2.927 \\
\hline Brunei & 4 & 0.002 & -3.451 & Guinea & 5 & -0.019 & -2.337 \\
\hline Cameroon & 4 & 0.002 & -0.611 & Mauritania & 5 & -0.021 & -3.141 \\
\hline Gabon & 4 & 0.002 & -2.442 & Sierra Leone & 5 & -0.023 & -3.015 \\
\hline Bangladesh & 4 & 0.001 & 0.198 & Afghanistan & 5 & -0.024 & -3.290 \\
\hline Panama & 4 & 0.001 & -0.759 & Yemen & 5 & -0.025 & -0.917 \\
\hline Jordan & 4 & 0.000 & 1.250 & Burkina Faso & 5 & -0.028 & -3.034 \\
\hline Honduras & 4 & 0.000 & -2.342 & Somalia & 5 & -0.029 & -1.835 \\
\hline Jamaica & 4 & -0.001 & -2.744 & Belize & 5 & -0.032 & -2.856 \\
\hline Sudan & 4 & -0.001 & -0.615 & Central African Rep. & 5 & -0.033 & -3.734 \\
\hline Paraguay & 4 & -0.002 & -2.175 & Benin & 6 & -0.039 & -2.383 \\
\hline Dominican Republic & 4 & -0.002 & -2.107 & Kiribati & 6 & -0.040 & -4.346 \\
\hline El Salvador & 4 & -0.002 & -3.205 & Burundi & 6 & -0.040 & -3.995 \\
\hline Papua New Guinea & 4 & -0.002 & -3.062 & Rwanda & 6 & -0.041 & -3.761 \\
\hline Bolivia & 4 & -0.002 & -1.512 & Nepal & 6 & -0.042 & -3.134 \\
\hline Iceland & 4 & -0.003 & -2.185 & Guinea-Bissau & 6 & -0.043 & -3.582 \\
\hline Tanzania & 4 & -0.004 & -0.259 & Mongolia & 6 & -0.046 & -4.081 \\
\hline Liberia & 4 & -0.004 & -0.332 & Djibouti & 6 & -0.046 & -2.274 \\
\hline Ghana & 4 & -0.004 & -1.067 & French Guiana & 6 & -0.048 & -3.416 \\
\hline North Korea & 4 & -0.004 & -2.002 & Gibraltar & 6 & -0.050 & -3.332 \\
\hline Senegal & 4 & -0.005 & -1.302 & Bermuda & 6 & -0.051 & -2.191 \\
\hline
\end{tabular}




\section{JOURNAL OF WORLD-SYSTEMS RESEARCH}

Table A1b continued

\begin{tabular}{|c|c|c|c|c|c|c|c|}
\hline Nicaragua & 4 & -0.005 & -3.519 & Solomon Islands & 6 & -0.052 & -3.976 \\
\hline Cyprus & 4 & -0.006 & -0.567 & Chad & 6 & -0.053 & -2.815 \\
\hline Myanmar & 4 & -0.007 & -2.552 & Gambia & 6 & -0.057 & -2.999 \\
\hline Niger & 4 & -0.009 & -2.806 & Equatorial Guinea & 6 & -0.063 & -2.669 \\
\hline Mozambique & 4 & -0.009 & -1.680 & Laos & 6 & -0.065 & -3.597 \\
\hline Madagascar & 4 & -0.010 & -2.229 & Comoros & 6 & -0.070 & -3.725 \\
\hline Suriname & 4 & -0.011 & -3.098 & Bhutan & 6 & -0.070 & -3.061 \\
\hline Ethiopia & 4 & -0.012 & -1.250 & Cambodia & 6 & -0.073 & -3.401 \\
\hline New Caledonia & 4 & -0.013 & -2.640 & Seychelles & 6 & -0.085 & -3.799 \\
\hline Togo & 4 & -0.013 & -1.967 & St Pierre \& Miquelon & 6 & -0.089 & -2.522 \\
\hline Guyana & 4 & -0.013 & -3.386 & Falkland Islands & 6 & -0.090 & -3.358 \\
\hline Malta & 4 & -0.014 & -1.197 & Maldives & 6 & -0.093 & -4.279 \\
\hline Saint Kitts and Nevis & 4 & -0.015 & -3.200 & Western Sahara & 6 & -0.101 & -0.556 \\
\hline Haiti & 4 & -0.015 & -2.690 & Turks \& Caicos Is. & 6 & -0.106 & -2.030 \\
\hline Mauritius & 4 & -0.015 & -2.663 & St Helena & 6 & -0.111 & -2.182 \\
\hline Congo & 5 & -0.015 & -1.874 & Cayman Islands & 6 & -0.111 & -1.593 \\
\hline Greenland & 5 & -0.015 & -1.838 & Br. Indian Ocean Ter & 6 & -0.224 & -1.598 \\
\hline Guadeloupe & 5 & -0.016 & -1.850 & & & & \\
\hline
\end{tabular}

Table A2a: Core and Semi-Periphery in 1980, ranked by position and CA of RE

\begin{tabular}{|c|c|c|c|c|c|c|c|}
\hline Country & Position & CA of RE & EDM & Country & Position & CA of RE & EDM \\
\hline & & 1st Dim & 1st Dim & & & 1st Dim & 1st Dim \\
\hline United States & 1 & 0.075 & 7.962 & South Africa & 2 & 0.027 & 7.413 \\
\hline Germany & 1 & 0.068 & 9.255 & Hungary & 2 & 0.026 & 7.207 \\
\hline France & 1 & 0.062 & 8.408 & Argentina & 2 & 0.026 & 2.561 \\
\hline Italy & 1 & 0.060 & 8.224 & Czech Republic & 2 & 0.025 & 7.111 \\
\hline United Kingdom & 1 & 0.059 & 8.818 & Ukraine & 2 & 0.025 & 3.477 \\
\hline Japan & 1 & 0.058 & 8.464 & Portugal & 2 & 0.023 & 5.276 \\
\hline China & 1 & 0.055 & 7.648 & Greece & 2 & 0.023 & 6.751 \\
\hline Netherlands & 1 & 0.050 & 8.716 & Venezuela & 2 & 0.023 & 2.230 \\
\hline Belgium-Luxembourg & 1 & 0.049 & 8.162 & Philippines & 2 & 0.022 & 4.760 \\
\hline South Korea & 1 & 0.049 & 7.980 & Iran & 3 & 0.023 & 1.203 \\
\hline Spain & 1 & 0.048 & 8.181 & Chile & 3 & 0.021 & 2.253 \\
\hline Singapore & 1 & 0.041 & 7.908 & Vietnam & 3 & 0.021 & 3.370 \\
\hline Taiwan & 2 & 0.045 & 4.269 & Nigeria & 3 & 0.019 & 1.502 \\
\hline Russia & 2 & 0.043 & 5.661 & Romania & 3 & 0.019 & 4.241 \\
\hline Hong Kong & 2 & 0.041 & 7.351 & New Zealand & 3 & 0.018 & 3.405 \\
\hline Switzerland & 2 & 0.039 & 8.600 & Algeria & 3 & 0.018 & 0.397 \\
\hline
\end{tabular}


Table A2a continued

\begin{tabular}{|c|c|c|c|c|c|c|c|}
\hline Brazil & 2 & 0.038 & 7.151 & Colombia & 3 & 0.016 & 3.325 \\
\hline India & 2 & 0.037 & 6.759 & Kuwait & 3 & 0.016 & -0.523 \\
\hline Sweden & 2 & 0.037 & 8.621 & Pakistan & 3 & 0.015 & 4.398 \\
\hline Canada & 2 & 0.036 & 7.918 & Slovakia & 3 & 0.015 & 2.959 \\
\hline Thailand & 2 & 0.036 & 7.029 & Slovenia & 3 & 0.014 & 3.237 \\
\hline Malaysia & 2 & 0.034 & 7.571 & Morocco & 3 & 0.014 & 3.268 \\
\hline Austria & 2 & 0.033 & 8.429 & Kazakhstan & 3 & 0.014 & 0.177 \\
\hline Australia & 2 & 0.033 & 7.369 & Libya & 3 & 0.012 & -2.084 \\
\hline Turkey & 2 & 0.033 & 7.504 & Peru & 3 & 0.012 & 1.376 \\
\hline Mexico & 2 & 0.032 & 7.518 & Oman & 3 & 0.011 & -0.448 \\
\hline Finland & 2 & 0.031 & 5.643 & Tunisia & 3 & 0.011 & 1.770 \\
\hline Denmark & 2 & 0.031 & 7.991 & Belarus & 3 & 0.010 & -1.220 \\
\hline Indonesia & 2 & 0.030 & 6.196 & Croatia & 3 & 0.010 & 2.574 \\
\hline Saudi Arabia & 2 & 0.030 & 7.208 & Bulgaria & 3 & 0.009 & 2.570 \\
\hline Ireland & 2 & 0.030 & 7.607 & Lithuania & 3 & 0.008 & -1.088 \\
\hline Poland & 2 & 0.030 & 6.170 & Ecuador & 3 & 0.008 & 0.277 \\
\hline Norway & 2 & 0.028 & 5.916 & Trinidad \& Tobago & 3 & 0.007 & -1.238 \\
\hline United Arab Emirates & 2 & 0.028 & 7.129 & Netherlands Antilles & 3 & 0.005 & -2.573 \\
\hline Israel & 2 & 0.027 & 5.134 & Equatorial Guinea & 3 & -0.019 & -5.331 \\
\hline
\end{tabular}

Table A2b: Periphery in 2001, ranked by position and CA of RE

\begin{tabular}{lccccccc}
\multicolumn{1}{c}{ Country } & Position & CA of RE & EDM & Country & Position & CA of RE & EDM \\
& & & 1st Dim & 1st Dim & & 1st Dim & 1st Dim \\
Iraq & 4 & 0.013 & -2.436 & Nepal & 4 & -0.014 & -5.579 \\
Egypt & 4 & 0.012 & 4.978 & Cambodia & 4 & -0.014 & -4.301 \\
Syria & 4 & 0.009 & -0.713 & Mongolia & 4 & -0.016 & -4.853 \\
Costa Rica & 4 & 0.009 & -1.095 & Greenland & 4 & -0.020 & -4.403 \\
Estonia & 4 & 0.007 & 1.057 & Haiti & 4 & -0.020 & -4.573 \\
Qatar & 4 & 0.007 & -0.910 & Tanzania & 5 & -0.012 & -0.483 \\
Bangladesh & 4 & 0.006 & 1.633 & Mozambique & 5 & -0.014 & -3.688 \\
Guatemala & 4 & 0.006 & -0.892 & Madagascar & 5 & -0.014 & -3.154 \\
Cote d'Ivoire & 4 & 0.005 & -2.658 & Saint Kitts and Nevis & 5 & -0.015 & -1.407 \\
Sri Lanka & 4 & 0.005 & 0.073 & Fiji & 5 & -0.015 & -4.616 \\
Jordan & 4 & 0.004 & 0.829 & Ethiopia & 5 & -0.015 & -0.210 \\
Bahrain & 4 & 0.004 & -0.421 & Uganda & 5 & -0.016 & -2.221 \\
Yugoslavia & 4 & 0.002 & 2.127 & Guyana & 5 & -0.017 & -5.655 \\
Latvia & 4 & 0.002 & -1.607 & Guinea & 5 & -0.017 & -3.014 \\
Angola & 4 & 0.002 & -1.758 & Georgia & 5 & -0.018 & -3.443
\end{tabular}




\section{JOURNAL OF WORLD-SYSTEMS RESEARCH}

Table A2b continued

\begin{tabular}{|c|c|c|c|c|c|c|c|}
\hline Panama & 4 & 0.001 & -1.390 & Mali & 5 & -0.019 & -1.307 \\
\hline Uzbekistan & 4 & 0.001 & -4.103 & Laos & 5 & -0.019 & -5.226 \\
\hline El Salvador & 4 & 0.001 & -2.040 & Bermuda & 5 & -0.020 & -4.343 \\
\hline Uruguay & 4 & 0.001 & -0.906 & Barbados & 5 & -0.020 & -2.730 \\
\hline Kenya & 4 & 0.001 & -1.433 & Malawi & 5 & -0.020 & -4.373 \\
\hline Honduras & 4 & 0.000 & -2.893 & Suriname & 5 & -0.020 & -6.570 \\
\hline Jamaica & 4 & -0.001 & -3.260 & Mauritania & 5 & -0.022 & -4.115 \\
\hline Yemen & 4 & -0.001 & -2.009 & Cayman Islands & 5 & -0.023 & -3.404 \\
\hline Dominican Republic & 4 & -0.001 & -0.939 & Tajikistan & 5 & -0.023 & -5.913 \\
\hline Myanmar & 4 & -0.001 & -4.845 & Gibraltar & 5 & -0.025 & -5.202 \\
\hline Ghana & 4 & -0.002 & 0.305 & Kyrgyzstan & 5 & -0.026 & -6.041 \\
\hline Cuba & 4 & -0.002 & 0.305 & Togo & 5 & -0.026 & -3.401 \\
\hline Malta & 4 & -0.002 & -0.745 & Benin & 5 & -0.026 & -1.999 \\
\hline Lebanon & 4 & -0.003 & 4.616 & Belize & 5 & -0.026 & -5.587 \\
\hline Cyprus & 4 & -0.003 & 2.947 & Armenia & 5 & -0.027 & -5.038 \\
\hline Sudan & 4 & -0.004 & 0.596 & Niger & 5 & -0.028 & -4.160 \\
\hline Iceland & 4 & -0.004 & -0.819 & Kiribati & 5 & -0.029 & -5.978 \\
\hline Paraguay & 4 & -0.004 & -3.587 & Guinea-Bissau & 5 & -0.030 & -4.809 \\
\hline Cameroon & 4 & -0.005 & -1.802 & Afghanistan & 5 & -0.030 & -5.962 \\
\hline Papua New Guinea & 4 & -0.005 & -4.880 & Burkina Faso & 5 & -0.031 & -4.314 \\
\hline Bosnia \& Herzegovina & 4 & -0.005 & -3.937 & Somalia & 5 & -0.031 & -5.673 \\
\hline Mauritius & 4 & -0.006 & -1.855 & Djibouti & 6 & -0.032 & -5.309 \\
\hline North Korea & 4 & -0.006 & -2.098 & Rwanda & 6 & -0.037 & -4.323 \\
\hline Macau & 4 & -0.006 & -3.081 & Maldives & 6 & -0.041 & -5.354 \\
\hline Turkmenistan & 4 & -0.006 & -5.443 & Sierra Leone & 6 & -0.044 & -4.279 \\
\hline Zimbabwe & 4 & -0.006 & -3.527 & Chad & 6 & -0.048 & -5.126 \\
\hline Liberia & 4 & -0.006 & -4.340 & Br. Indian Ocean Ter. & 6 & -0.048 & -3.388 \\
\hline Macedonia & 4 & -0.006 & -2.405 & Falkland Islands & 6 & -0.049 & -4.176 \\
\hline Bolivia & 4 & -0.007 & -3.799 & Comoros & 6 & -0.050 & -6.169 \\
\hline Senegal & 4 & -0.007 & -1.244 & Gambia & 6 & -0.053 & -5.197 \\
\hline Gabon & 4 & -0.008 & -4.482 & Seychelles & 6 & -0.053 & -5.375 \\
\hline Azerbaijan & 4 & -0.008 & -3.302 & Burundi & 6 & -0.055 & -5.862 \\
\hline Brunei & 4 & -0.008 & -5.117 & Central African Rep. & 6 & -0.055 & -5.642 \\
\hline Zambia & 4 & -0.009 & -4.574 & Bhutan & 6 & -0.059 & -5.144 \\
\hline Nicaragua & 4 & -0.009 & -4.208 & Turks \& Caicos Is. & 6 & -0.062 & -5.215 \\
\hline Moldova & 4 & -0.010 & -3.562 & Solomon Islands & 6 & -0.066 & -4.881 \\
\hline Congo & 4 & -0.011 & -3.392 & St Pierre \& Miquelon & 6 & -0.077 & -2.575 \\
\hline New Caledonia & 4 & -0.011 & -1.242 & St Helena & 6 & -0.095 & -5.083 \\
\hline Bahamas & 4 & -0.012 & -2.822 & Western Sahara & 6 & -0.109 & -1.426 \\
\hline Albania & 4 & -0.014 & -3.758 & Reunion & 6 & -0.166 & -1.660 \\
\hline Zaire & 4 & -0.014 & -4.260 & & & & \\
\hline
\end{tabular}

